Article

\title{
Illuminating the Capabilities of the Suomi National Polar-Orbiting Partnership (NPP) Visible Infrared Imaging Radiometer Suite (VIIRS) Day/Night Band
}

\author{
Steven D. Miller ${ }^{1, *}$, William Straka, III ${ }^{2}$, Stephen P. Mills ${ }^{3}$, Christopher D. Elvidge ${ }^{4}$, \\ Thomas F. Lee ${ }^{5}$, Jeremy Solbrig ${ }^{5}$, Andi Walther ${ }^{2}$, Andrew K. Heidinger ${ }^{6}$ \\ and Stephanie C. Weiss ${ }^{7}$
}

1 Cooperative Institute for Research in the Atmosphere, Colorado State University, Fort Collins, CO 80523, USA

2 Cooperative Institute for Meteorological Satellite Studies, University of Wisconsin-Madison, Madison, WI 53706, USA; E-Mails: William.Straka@ssec.wisc.edu (W.S.);

Andi.Walther@ssec.wisc.edu (A.W.)

3 Renaissance Man Engineering, Glendale, CA 91202, USA; E-Mail: steve@renmaneng.com

4 National Geophysical Data Center, National Satellite, Data and Information Service, National Oceanic and Atmospheric Administration, Boulder, CO 80305, USA;

E-Mail: Chris.Elvidge@noaa.gov

5 Satellite Meteorological Applications Section, Marine Meteorology Division, Monterey Naval Research Laboratory, CA 93907, USA; E-Mails: tomlee@redshift.com (T.F.L.); 7541@nrlmry.navy.mil (J.S.)

6 Center for Satellite Applications and Research, Advanced Satellite Products Branch, National Satellite, Data and Information Service, National Oceanic and Atmospheric Administration, Madison, WI 53706, USA; E-Mail: Andrew.Heidinger@noaa.gov

7 Northrop Grumman Aerospace Systems, Redondo Beach, CA 90278, USA;

E-Mail: Stephanie.Weiss@ngc.com

* Author to whom correspondence should be addressed; E-Mail: Steven.Miller@colostate.edu; Tel.: +1-970-491-8037; Fax: +1-970-491-8241.

Received: 30 September 2013; in revised form: 12 November 2013 / Accepted: 13 November 2013 / Published: 6 December 2013

\footnotetext{
Abstract: Daytime measurements of reflected sunlight in the visible spectrum have been a staple of Earth-viewing radiometers since the advent of the environmental satellite platform. At night, these same optical-spectrum sensors have traditionally been limited to thermal infrared emission, which contains relatively poor information content for many
} 
important weather and climate parameters. These deficiencies have limited our ability to characterize the full diurnal behavior and processes of parameters relevant to improved monitoring, understanding and modeling of weather and climate processes. Visible-spectrum light information does exist during the nighttime hours, originating from a wide variety of sources, but its detection requires specialized technology. Such measurements have existed, in a limited way, on USA Department of Defense satellites, but the Suomi National Polar-orbiting Partnership (NPP) satellite, which carries a new Day/Night Band (DNB) radiometer, offers the first quantitative measurements of nocturnal visible and near-infrared light. Here, we demonstrate the expanded potential for nocturnal low-light visible applications enabled by the DNB. Via a combination of terrestrial and extraterrestrial light sources, such observations are always available - expanding many current existing applications while enabling entirely new capabilities. These novel low-light measurements open doors to a wealth of new interdisciplinary research topics while lighting a pathway toward the optimized design of follow-on satellite based low light visible sensors.

Keywords: satellite imagery; nighttime visible/near-infrared; moonlight

\section{Introduction}

The National Polar-orbiting Partnership (NPP) satellite is the first in a series of next-generation USA operational environmental satellites constituting the Joint Polar Satellite System (JPSS). The satellite emerged from partnership between the National Aeronautics and Space Administration (NASA) and the National Oceanic and Atmospheric Administration (NOAA). Upon its successful launch and placement into a sun-synchronous 1330 local time ascending node orbit on 28 October 2011, it was renamed "Suomi NPP", (hereafter, S-NPP) in honor of environmental satellite pioneer Verner E. Suomi [1]. From its $824 \mathrm{~km}$ orbital altitude, S-NPP completes a single Earth orbit in 102 min, thus providing global coverage via $\sim 14$ orbits per day. The five earth-observing sensors carried on board S-NPP (namely, the Visible Infrared Imaging Radiometer Suite (VIIRS), the Cross-track Infrared Sounder (CrIS), the Advanced Technology Microwave Sounder (ATMS), the Ozone Mapping and Profiler Suite (OMPS), and the Clouds and the Earth's Radiant Energy System (CERES)) were intended to provide improved analyses for NOAA's operational weather forecasts and continuity to NASA's research in climate change, the earth's energy budget, and the global cycling of water and carbon.

The VIIRS instrument on S-NPP combines capabilities of heritage operational and contemporary research-grade observing systems. VIIRS provides 22 narrowband channels spanning the optical spectrum $(0.4-12 \mu \mathrm{m})$ derived from three legacy instruments: the NOAA Advanced Very High Resolution Radiometer (AVHRR), the NASA Moderate Resolution Imaging Spectroradiometer (MODIS), and the Defense Meteorological Satellite Program (DMSP) Operational Linescan System (OLS). An important enhancement is the Day/Night Band (DNB; [2]), which in addition to conventional daytime visible imaging provides a unique ability to sense extremely low-levels of visible/near-infrared light at night down to levels more than 10 million times fainter than reflected sunlight. Strictly speaking, half of the DNB response (roughly, 500-900 nm, full width/half maximum) 
resides at wavelengths beyond visible-band red light, but hereafter we shall refer to its response loosely as being a "low-light visible" sensor. As the legacy DMSP/OLS measurements have been used predominately within the Department of Defense (DoD) user community for uncalibrated weather imagery, the VIIRS/DNB calibrated radiance represents an new capability to most users. A goal of this paper is to demonstrate how low-light visible measurement capabilities can serve both the research and operational communities.

Figure 1. Conceptual diagram of various nocturnal environment parameters observable under conditions of (a) lunar illumination, and (b) on moon-free nights. (Courtesy of Steve Deyo, UCAR COMET Program).

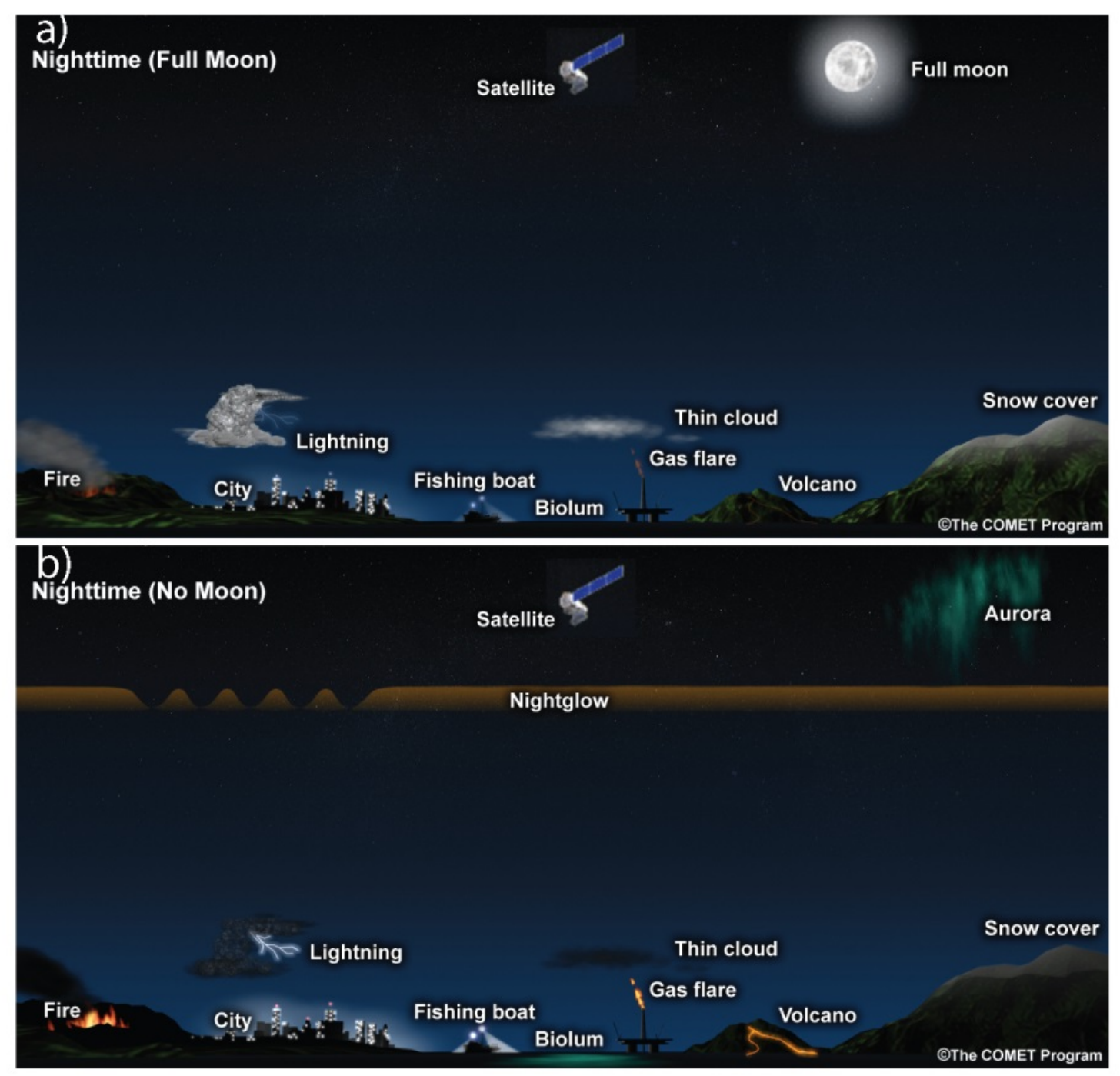

Daytime measurements of reflected sunlight have been a mainstay of Earth-viewing optical-spectrum radiometers since the Television Infrared Observation Satellite (TIROS) sensor provided the first "television picture" from space on 1 April 1960 (e.g., [3]). At night, these conventional radiometers are relegated to collecting only thermal infrared emission. While such measurements contain unique and valuable information, by themselves they cannot discriminate between objects of similar temperature and emissivity properties, a particular problem at night when solar measurements are absent. In other 
cases they may provide adequate detection of a parameter, but lack sensitivity to its physical properties. These deficiencies at night limit our ability to characterize the diurnal behavior and processes of various parameters relevant to the monitoring and modeling of weather and climate-it would be ideal to have the same quality of information both day and night.

Visible light is ubiquitous at night but confined to very low intensities compared to daytime. For example, the typical brightness of a moonlit scene is roughly five to six orders of magnitude fainter than a day lit scene. With the DNB's sensitivity to very minute signals, however, it becomes readily apparent that the night is never truly dark. As shown in Figure 1 (adapted from [2]), the night is replete with visible light sources even without the presence of moonlight, arising from both of natural and artificial (anthropogenic) sources.

Table 1 provides further details on selected nocturnal parameters where low-light visible holds information content, either as a stand-alone measurement or in concert with other spectral bands.

Table 1. Examples of Day/Night Band (DNB)-measurable parameters at night, and associated challenges.

\begin{tabular}{|c|c|c|c|}
\hline Measurement Objective & $\begin{array}{l}\text { Primary Light } \\
\text { Source (s) }\end{array}$ & $\begin{array}{l}\text { Accompanying VIIRS } \\
\text { Bands Required }(\mu \mathrm{m})\end{array}$ & $\begin{array}{l}\text { Challenges, Limitations, } \\
\text { Contamination }\end{array}$ \\
\hline $\begin{array}{l}\text { Near-Constant Contrast } \\
\text { Standard Imagery }\end{array}$ & All & N/A & Stray Light Contamination \\
\hline Lunar Reflectance Imagery & Lunar & N/A & $\begin{array}{l}\text { Lunar Model Uncertainty, } \\
\text { Astronomical Dark Only }\end{array}$ \\
\hline Sea/Lake Ice Mask & Lunar & N/A & Cloud Obscuration \\
\hline Snow Cover Mask & Lunar & $\mathrm{N} / \mathrm{A}$ & $\begin{array}{l}\text { Cloud Obscuration \& Artificial } \\
\text { Light Contamination }\end{array}$ \\
\hline Cloud Cover Mask & Lunar & $3.7,4.05,8.55,10.8,12.0$ & Artificial Light Contamination \\
\hline Cloud Eff. Particle Size & Lunar & $3.7,8.55,10.8,12.0$ & Artificial Light Contamination \\
\hline Cloud Optical Depth & Lunar & $3.7,8.55,10.8,12.0$ & Artificial Light Contamination \\
\hline $\begin{array}{l}\text { Cloud Top Height, Pressure, } \\
\& \text { Temperature }\end{array}$ & Lunar & $\begin{array}{l}3.7,4.05,8.55,10.8 \\
12.0\end{array}$ & Artificial Light Contamination \\
\hline $\begin{array}{l}\text { Tropical Cyclone } \\
\text { Low-Level Circulation }\end{array}$ & Lunar & 10.8 & High Cloud Obscuration \\
\hline Storm Electrification & Lightning & 10.8 & $\begin{array}{l}\text { Artificial Light Contamination, } \\
\text { Non-Staring Sensor }\end{array}$ \\
\hline Biomass Burning & Flames & $2.25,4.05,10.8,12.0$ & Artificial Light Contamination \\
\hline Biomass Smoke & Lunar & $8.55,10.8,12.0$ & Limited Geometries \\
\hline Surface Type & Lunar & $3.7,4.05,8.55,10.8,12.0$ & Near-IR Bands Unavailable \\
\hline Soil Moisture & Lunar & $\begin{array}{l}3.7,4.05,8.55,10.8 \\
12.0\end{array}$ & Certain Surface Types \\
\hline Water Turbidity & Lunar & $\mathrm{N} / \mathrm{A}$ & Gross Detection for Significant Events \\
\hline Bioluminescence (Ocean) & $\begin{array}{l}\text { Luminous Bacteria, } \\
\text { Dinoflagellates }\end{array}$ & $\mathrm{N} / \mathrm{A}$ & $\begin{array}{l}\text { Cloud Obscuration, Unconfirmed } \\
\text { for DNB }\end{array}$ \\
\hline $\begin{array}{l}\text { Internal Waves, Sea Surface } \\
\text { Currents }\end{array}$ & Lunar & N/A & $\begin{array}{l}\text { Cloud Obscuration, Valid for Glint } \\
\text { Zone Only }\end{array}$ \\
\hline
\end{tabular}


Table 1. Cont.

\begin{tabular}{|c|c|c|c|}
\hline Measurement Objective & $\begin{array}{l}\text { Primary Light } \\
\text { Source (s) }\end{array}$ & $\begin{array}{l}\text { Accompanying VIIRS Bands } \\
\text { Required }(\mu \mathrm{m})\end{array}$ & $\begin{array}{l}\text { Challenges, Limitations, } \\
\text { Contamination }\end{array}$ \\
\hline Aerosol Optical Depth (Ocean) & $\begin{array}{l}\text { Lunar or Stable } \\
\text { Anthro. Lights }\end{array}$ & $8.55,10.8,12.0$ & N/A in Glint Zone \\
\hline Volcanic Ash Mask & Lunar & $3.7,8.55,10.8,12.0$ & Cloud Obscuration \\
\hline Pyroclastic Flow & Molten Lava & $2.25,3.7,10.8$ & $\begin{array}{l}\text { Ambiguity with Lava-Induced } \\
\text { Fires }\end{array}$ \\
\hline Lofted Dust Mask (Ocean) & Lunar & $8.55,10.8,12.0$ & Cloud Obscuration \\
\hline $\begin{array}{l}\text { Human Settlements and } \\
\text { Economic Activity/Change }\end{array}$ & City Lights & N/A & Cloud Diffusion \\
\hline $\begin{array}{l}\text { Power Consumption \& Power } \\
\text { Outages }\end{array}$ & City Lights & N/A & Clear Sky Only \\
\hline $\mathrm{CO}_{2}$ Emissions & City Lights, Flares & N/A & Clear Sky Only \\
\hline Ship Monitoring & Ship Lights & N/A & Clear Sky Only \\
\hline Fossil Fuel Mining & Natural Gas Flares & $1.61,2.25,3.7$ & Clear Sky Only \\
\hline Solar Storms & Auroral Light & $\mathrm{N} / \mathrm{A}$ & $\begin{array}{l}\text { Ambiguity with Clouds on Lunar } \\
\text { Nights }\end{array}$ \\
\hline Mesospheric Gravity Waves & Nightglow & N/A & $\begin{array}{l}\text { Moon-Free, Astronomical Dark } \\
\text { Conditions Only }\end{array}$ \\
\hline
\end{tabular}

This paper guides the reader on an illustrative review of the many potential applications possible from nocturnal low-light visible satellite observations, revealing a wealth of information heretofore beyond our reach, and in some cases, our imagination. Section 2 provides a description of new VIIRS/DNB observations, placed in the context of legacy measurements. These measurements provide a new perspective on many facets of the Earth/atmosphere system. Section 3 presents selected examples of these capabilities while offering a glance toward new frontiers of science. Section 4 expands on the many research and operational possibilities afforded by these measurements. With an eye toward improved future low-light sensors, Section 5 imagines an idealized platform and design. Section 6 concludes the paper with a summary of the findings and a perspective on the path ahead.

\section{VIIRS Day/Night Band Sensor Description}

As noted in Figure 1, the DNB measures signals from the Earth and atmosphere-daytime solar and nighttime lunar reflectance as well as both natural and artificial nighttime light emissions. The DMSP/OLS provides a similar detection capability, but principally in a qualitative sense due to the lack of calibration, radiometric limitations and relatively poor geolocation accuracy. Table 2 summarizes some of the principal differences between the VIIRS/DNB and DMSP/OLS sensors.

One of the key advances of the DNB over the OLS is with regard to spatial resolution. Full details of the OLS data collection strategy are outlined by [4]. To summarize the salient points here, the OLS acquires data in two spatial resolution modes: "fine" mode collected at $0.56 \mathrm{~km}$ horizontal sampling interval (HSI; or pixel-to-pixel spacing), and a "smooth" mode wherein five-by-five blocks of fine-mode imagery are averaged on-board the satellite to produce nominal $2.8 \mathrm{~km}$ HSI. However, it is the horizontal spatial resolution (HSR) which defines the inherent ability to resolve feature of a certain 
spatial scale. The significantly smaller HSR for the DNB accounts for the vast improvement in spatial detail between DNB and OLS. In particular, the geometric area of the Earth's surface viewed by the VIIRS/DNB data is approximately a $0.75 \mathrm{~km} \times 0.75 \mathrm{~km}\left(\sim 0.56 \mathrm{~km}^{2}\right)$, in contrast to the OLS approximate values of $5 \mathrm{~km} \times 5 \mathrm{~km}$ at nadir and $7 \mathrm{~km} \times 7 \mathrm{~km}$ at scan edge. In consequence, the DNB spatial resolution is in fact about 45 times higher than that of the OLS at nadir, and 88 times higher at scan edge $[5,6]$. Since the HSR is much larger than the HSI for the OLS, considerable oversampling is present between adjacent pixels and features in the imagery therefore tend to appear "fuzzier" than what might be expected for $2.8 \mathrm{~km}$ pixels sizes. Conversely, due to similar sizes of HSR and HSI for the DNB, features appear more sharply defined and representative of what would be expected for $\sim 0.75 \mathrm{~km}$ pixel sizes.

Table 2. Comparison between the Suomi National Polar-orbiting Partnership (S-NPP) Visible Infrared Imaging Radiometer Suite (VIIRS)/DNB and heritage DMSP/Operational Linescan System (OLS) (nighttime smooth-mode data).

\begin{tabular}{|c|c|c|}
\hline Attribute & DMSP/OLS & VIIRS/DNB \\
\hline Orbital Details & Sun-synchronous, $\sim 850 \mathrm{~km}$ & Sun-synchronous, 824 km \\
\hline Nighttime Nodal Overpass Time & $\sim 1930$ UTC & $\sim 0130$ UTC \\
\hline Swath Width & $3000 \mathrm{~km}$ & $3000 \mathrm{~km}$ \\
\hline Spectral Passband Bandwidth & Panchromatic 500-900 nm & Panchromatic $500-900 \mathrm{~nm}$ \\
\hline Spectral Passband Center & $\sim 600 \mathrm{~nm}$ & $\sim 700 \mathrm{~nm}$ \\
\hline Horizontal Sampling Interval & 2.8 km (Nighttime “Smooth” Data) & $\begin{array}{c}0.740 \pm 0.043 \mathrm{~km}(\mathrm{Scan}) \\
0.755 \pm 0.022 \mathrm{~km}(\text { Track })\end{array}$ \\
\hline Horizontal Spatial Resolution & $5 \mathrm{~km}($ Nadir$) / \sim 7 \mathrm{~km}$ (Edge) & $\begin{array}{l}<0.770 \mathrm{~km}(\text { Scan }) \\
<0.750 \mathrm{~km}(\text { Track })\end{array}$ \\
\hline Geolocation Uncertainty & $\sim 450 \mathrm{~m}-5.4 \mathrm{~km}$ & $266 \mathrm{~m}$ (Nadir), $1151 \mathrm{~m}$ (Edge) \\
\hline Minimum Detectable Signal & $4 \times 10^{-5} \mathrm{~W} \cdot \mathrm{m}^{-2} \cdot \mathrm{sr}^{-1}$ & $3 \times 10^{-5} \mathrm{~W} \cdot \mathrm{m}^{-2} \cdot \mathrm{sr}^{-1}$ \\
\hline Noise Floor & $\sim 5 \times 10^{-6} \mathrm{~W} \cdot \mathrm{m}^{-2} \cdot \mathrm{sr}^{-1}$ & $\sim 5 \times 10^{-7} \mathrm{~W} \cdot \mathrm{m}^{-2} \cdot \mathrm{sr}^{-1}$ (Nadir) \\
\hline Radiometric Quantization & 6 bit & $13-14$ bit \\
\hline Accompanying Spectral Bands & 1 (Thermal IR) & 11 (Night)/21 (Day) \\
\hline Radiometric Calibration & None & On-Board Solar Diffuser \\
\hline Saturation, Stray Light Artifcats & Urban Cores, Substantial, Uncorrectable & None, Near-Terminator, Corrected \\
\hline
\end{tabular}

Pointing accuracy is also improved for the DNB compared to the OLS providing much more stable imagery from one night to the next. Unlike conventional sensors whose spatial resolution degrades from nadir toward the edge of scan, the DNB pixel size is maintained at nearly a constant value of $\sim 750 \mathrm{~m}$ sampling across its 3,000 km wide swath via a unique scan-angle-dependent sub-detector aggregation strategy [7]. As such, imagery resolution does not degrade with increasing distance from nadir, maintaining instead high resolution detail throughout the swath. The DNB scans cross-track (perpendicular to the direction of satellite motion), imaging 16 scan lines at a time, or roughly $12 \mathrm{~km}$ along-track sections per scan. There is a time separation of $1.78 \mathrm{~s}$ between adjacent scans, within which time the DNB images the Earth for $0.56 \mathrm{~s}$. The exact exposure time per pixel varies because of differences in aggregation across the scan, but is roughly $65 \mu \mathrm{s}$.

The DNB uses time delay integration (TDI) and a spectrally wide (panchromatic) band to enable the detection of dim signals within its spectral band pass. Whereas the nominal response of both the DNB 
and the OLS is panchromatic 500-900 nm, the DNB response is shifted toward slightly longer wavelengths, as shown in Figure 2. The DMSP response function shown here is for the F-12 satellite, but it is representative of the family of DMSP/OLS sensors within the limits of slight variation, which have a typical peak response near $600 \mathrm{~nm}$ (in contrast, the S-NPP VIIRS/DNB peak response is about $785 \mathrm{~nm}$ ). Significant implications of this ostensibly minor spectral shift in terms of detection capabilities will be discussed in the following section. In terms of in-band sensitivity, the nominal minimum detection in-band radiance for the DNB is $3 \times 10^{-5} \mathrm{~W} \cdot \mathrm{m}^{-2} \cdot \mathrm{sr}^{-1}$, specified at a signal-to-noise ratio (SNR) of $>5$ at edge-of-scan, and currently performing at an SNR $>9$. At this minimum detection level, the DNB is sensitive enough to detect the light emitted from a single isolated street lamp. As mentioned in Table 2, the actual noise floor of the sensor is $\sim 5 \times 10^{-7} \cdot \mathrm{W} \cdot \mathrm{m}^{-2} \cdot \mathrm{sr}^{-1}$ at nadir and $\sim 2 \times 10^{-6} \mathrm{~W} \cdot \mathrm{m}^{-2} \cdot \mathrm{sr}^{-1}$ at edge of scan [8-10]. To accommodate the very large dynamic range across day/night scenes, the DNB enlists digital gain selection, drawing from three simultaneously collecting gain stages (high, medium, low). These three stages correspond to different sections of the chargecoupled device (CCD) array with varied filtering and TDI. The low-gain stage is used for the daytime portions of the orbit, the medium-gain near the day/night terminator (twilight), and the high-gain on the night side of the orbit. Data from the three simultaneously collecting stages are digitized at 14 bits for the high gain and 13 bits for the medium and low gain stages. On-board digital logic selects, on a pixel-by-pixel basis, the most appropriate of the three stages to be transmitted down to Earth, corresponding to the most sensitive stage available providing unsaturated measurements.

Figure 2. Spectral response functions for the DNB and a representative nighttime OLS.

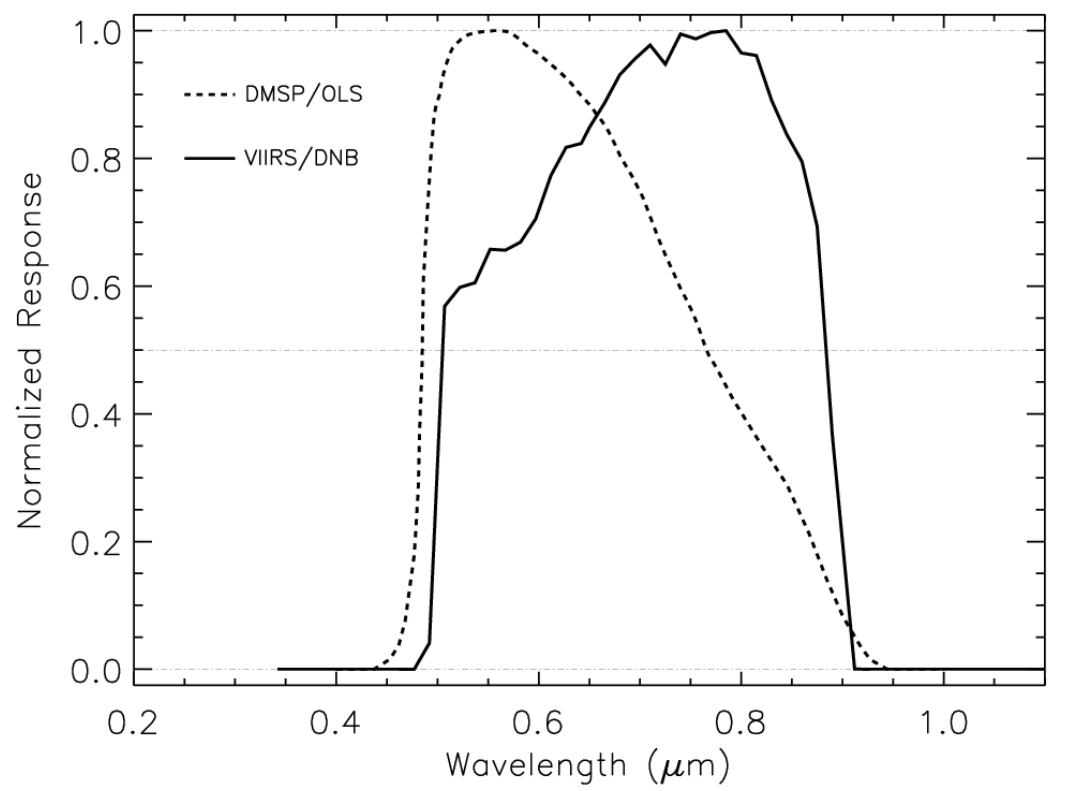

The DNB operates during both day and night portions of the orbit (hence "Day/Night"). The daytime operation is easy to overlook since most applications focus on the unique nighttime capabilities. However, the daytime operation is very important, in that it enables the DNB to take advantage of on-board calibration using the solar diffuser (which is used to calibrate all the reflective VIIRS bands). The daytime calibration of the low-gain stage is subsequently transferred to the terminator and nighttime portions of the orbit using regions where adjacent gain stage pairs both 
observe the scene in an unsaturated state $[9,10]$. The calibrated nature of DNB nighttime visible data, provided in units of in-band radiance, represents a significant advance over the uncalibrated OLS - enabling the first quantitative applications from low-light visible observations.

With its 0130 local time (descending node) nighttime overpass, S-NPP observes "lunar nights" (i.e., nights when the moon is above the horizon at the time of the satellite overpass) for one-half of the $\sim 29.5$ days lunar cycle. Sufficient lunar illumination is available from $\sim 2$ days past the First Quarter phase, through the Full Moon, until $\sim 2$ days past the Last Quarter. During this $\sim 2$ weeks period, the sensitivity of the DNB is more than sufficient to utilize the reflected lunar irradiance (on the order of $10^{-4} \mathrm{~W} \cdot \mathrm{m}^{-2}$ for a Full Moon) to produce imagery reminiscent of a day lit scene. Were it not for the tell-tale city lights, the occasional storm-top lightning flash, and lights emitted by ships, fires, etc., even experienced imagery analysts would be hard-pressed to distinguish between the two. With the assistance of a model for computing the top-of-atmosphere downwelling lunar irradiance spectra $\left(F_{m}\right.$, e.g., $[11,12])$, and convolving this spectra with the DNB spectral response function, one can calculate the scene reflectance and thereby relate the radiance measurements to physical properties of the scene in a way analogous to daytime measurements. The modeled irradiance is a function of date and time (used to determine the current lunar phase and Sun/Earth/Moon geometry). Using this lunar irradiance, the visible scene reflectance $(R)$ follows readily from the DNB radiance measurement $(I)$ and the cosine of the lunar zenith angle $\left(\mu_{\mathrm{m}}\right)$ as:

$$
R=\pi I / \mu_{m} F_{m}
$$

Figure 3 shows DNB imagery of Typhoon Jelawat in the western Pacific on a night when the moon is setting in the west at the time of the S-NPP overpass. The conversion from radiance (Figure 3a) to reflectance (Figure 3b) illustrates how the model normalizes the brightness of highly variable illumination. This improvement follows from inspection of the denominator of Equation (1), where the lunar irradiance term varies with the lunar cycle and is further modulated throughout the scene by its location in the sky (the cosine term). The main benefit and power of casting the observations in reflectance units is that it allows one to relate the measurements to the quantitative physical properties of the reflector-a topic revisited in the examples to follow and of particular importance to building useful diurnally-resolved climate data records for global cloud cover (e.g., [13]). The shortcomings include a strict assumption on solar-free and terrestrial-emission-free (e.g., Figure 1b) measurements - violation of this assumption will result in high-biased reflectance estimates that will impact quantitative and imagery applications negatively.

It is worthwhile to point out the differences between the lunar reflectance (Equation (1)) and what is provided by the "Near Constant-Contrast" (NCC) imagery that is currently available as a VIIRS/DNB environmental data record (EDR). The imagery that can be produced via through Equation (1) (shown in Figure 3b) is of similar appearance to NCC under moonlit conditions. However, the NCC computes a pseudo reflectance, drawing heritage from DMSP legacy algorithms, and includes a parameterized handling of twilight illumination near the terminator [14]. Since Equation (1) does not accommodate a diffuse solar (twilight) source, lunar reflectance imagery can be produced only in areas where there are no solar contributions (e.g., requires solar zenith angle $>\sim 109^{\circ}$ ) and moonlight is present. In contrast, NCC provides a continuous pseudo-reflectance across the terminator. As such, the NCC in its current 
form is appropriate for qualitative imagery purposes under all illumination conditions, and an approach following Equation (1) is recommended for quantitative lunar applications.

Figure 3. Application of lunar irradiance model to convert VIIRS/DNB observations of Typhoon Jelawat (25 September 2012, $1701 \mathrm{UTC}$ ). (a) In-band radiance $\left(\log _{10}\left[\mathrm{~W} \cdot \mathrm{cm}^{-2} \cdot \mathrm{sr}^{-1}\right]\right.$ ) units shows rapid darkening toward the lunar terminator (the Moon is low in western sky for this region at the time of the S-NPP overpass). (b) Reflectance (\%) units provide enhanced storm-top detail for lunar-illuminated portion of the scene.

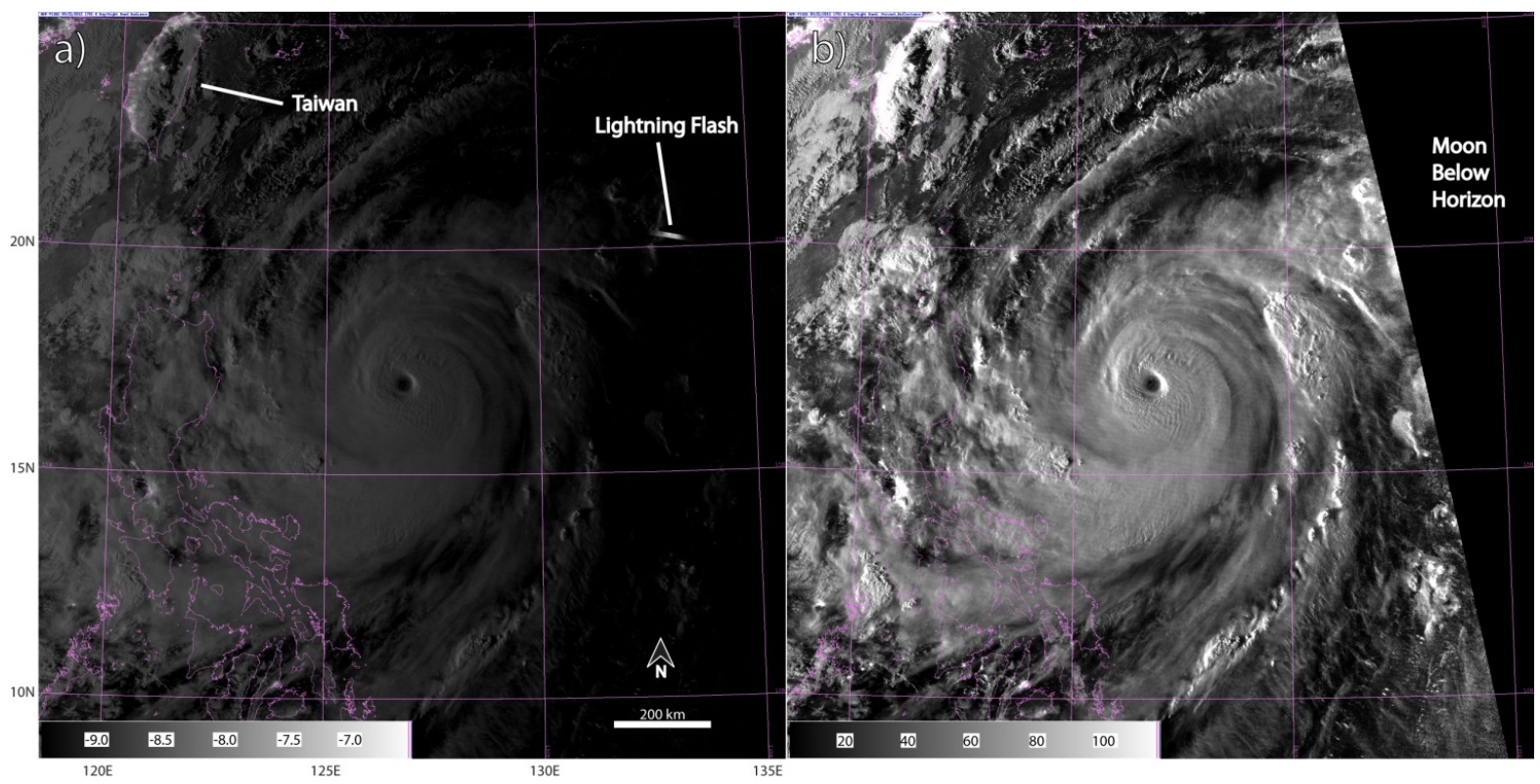

\section{Expanding our Sphere of Knowledge}

Despite our tendency to conduct scientific research along specialized and well-demarcated disciplinary lines, the Earth is best understood in a holistic sense; as a fully coupled network of systems with highly non-linear behaviors throughout. In order to understand and better predict both the natural variability of this system and its response to various external forcing mechanisms (e.g., climate change in response to volcanic eruptions or anthropogenic $\mathrm{CO}_{2}$ ), we must account for and properly characterize the interfaces and many feedback processes at play. Process-level understanding of the system requires the collection of global observations at the highest spatial, spectral, temporal, and radiometric resolution possible. Here, DNB low-light visible observations hold key information about diurnal variability of numerous parameters whose nocturnal property characterization at present is either severely limited or missing altogether.

This section offers a high level review of several S-NPP VIIRS/DNB capabilities, considering their value in the context of important aspects of Earth's many "spheres" of influence which they help to characterize - the cryosphere, hydrosphere, lithosphere, atmosphere and biosphere - the principal components of the holistic Earth system. In many of the comparisons to follow, the DNB imagery is shown alongside thermal infrared VIIRS observations (specifically, the M15 band centered at $10.763 \mu \mathrm{m})$. These are notional comparisons; they are not intended to marginalize the important and unique information content offered by the thermal bands, but rather, serve here to illustrate the 
first-order information content of the DNB. In practice, optimal exploitation of the DNB will be realized via multi-spectral synergy of the VIIRS bands (including the thermal bands) or other sensors on S-NPP which provide complementary information.

\subsection{The Cryosphere}

The cryosphere, consisting of Earth's permafrost, snow and ice-covered surfaces, is a key component of the hydrological cycle. It plays a central role in surface/atmosphere energy and moisture exchange and thus holds profound implications to global climate (e.g., [15]). High latitudes, where a majority of the cryosphere resides, experience significantly reduced amounts of sunlight during the polar winter. In the summer months, radiative forcing related to the high reflectivity of ice in contrast to the otherwise dark ocean waters play a critical role on the global circulation. Locations poleward of the Arctic and Antarctic Circles experience extended periods of darkness during the winter months and, in some cases, perpetual nighttime conditions. With its polar orbit, S-NPP provides relatively high re-visit rate to high latitudes. The examples to follow illustrate the particularly important and unique role played by the DNB in enhancing cryospheric observation capabilities.

\subsubsection{Mid-Latitude Snow Fields}

Knowledge of snow cover is important for determining land/atmosphere exchange (latent and sensible heat flux). The ability of multispectral satellite observations to distinguish snow cover from bare land and clouds during the daytime has led to important advances in the capacity of snow field monitoring [16-21]. However, challenges exist at night. For example, more rapid radiative cooling of boundary-layer air over snow fields can lead to the rapid formation of radiation fog (e.g., [22]) which poses visibility hazards to both surface and air transportation. Distinguishing snow fields at night from surrounding snow-free regions can prove challenging via thermal infrared imagery bands since the temperature contrasts are typically weak. DMSP/OLS moonlight imagery can be used to map the distribution of snow and ice features during the polar winter [23], and combined with Geostationary Operational Environmental Satellite (GOES) thermal bands to provide a multi-spectral nighttime snow mask [24]. Moonlight reflectance measurements from the DNB, combined with other VIIRS bands, now offer the potential to craft quantitative masking algorithms.

Figure 4 illustrates the advantages of DNB over thermal infrared in detecting snow cover at night. In Figure 4a, a S-NPP daytime pass of VIIRS true color imagery (composed of three daytime visible channels; M3 $(0.488 \mu \mathrm{m})$, M4 $(0.555 \mu \mathrm{m})$ and M5 $(0.672 \mu \mathrm{m})$; e.g., [25]) shows the extent of large snow field spanning parts of northeastern Colorado, northwestern Kansas, and southwestern Nebraska. The nighttime pass (Figure 4b) over this same region, collected on the following evening, shows the limitations of thermal infrared imagery. The ambiguity is due to similar temperatures between the snow cover and surrounding snow-free land. Finally, the corresponding DNB lunar reflectance imagery (Figure 4c) reveals the snow field in vivid detail reminiscent to the daytime observations. City lights along the Colorado Front Range, including Denver (as noted) preclude snow cover detection in these areas due to the strong light emission. 
Figure 4. (a) A large snow field is readily apparent in daytime (25 Mar 2013, 1955 UTC) VIIRS true color imagery. (b) The same snow field blends into the surrounding snow-free areas when viewed that next evening (26 March 2013, 0814 UTC) with VIIRS/M15 thermal infrared imagery (K). (c) The VIIRS Day/Night Band captures the same nighttime scene via lunar reflectance $(\%)$, revealing once again the snow field.
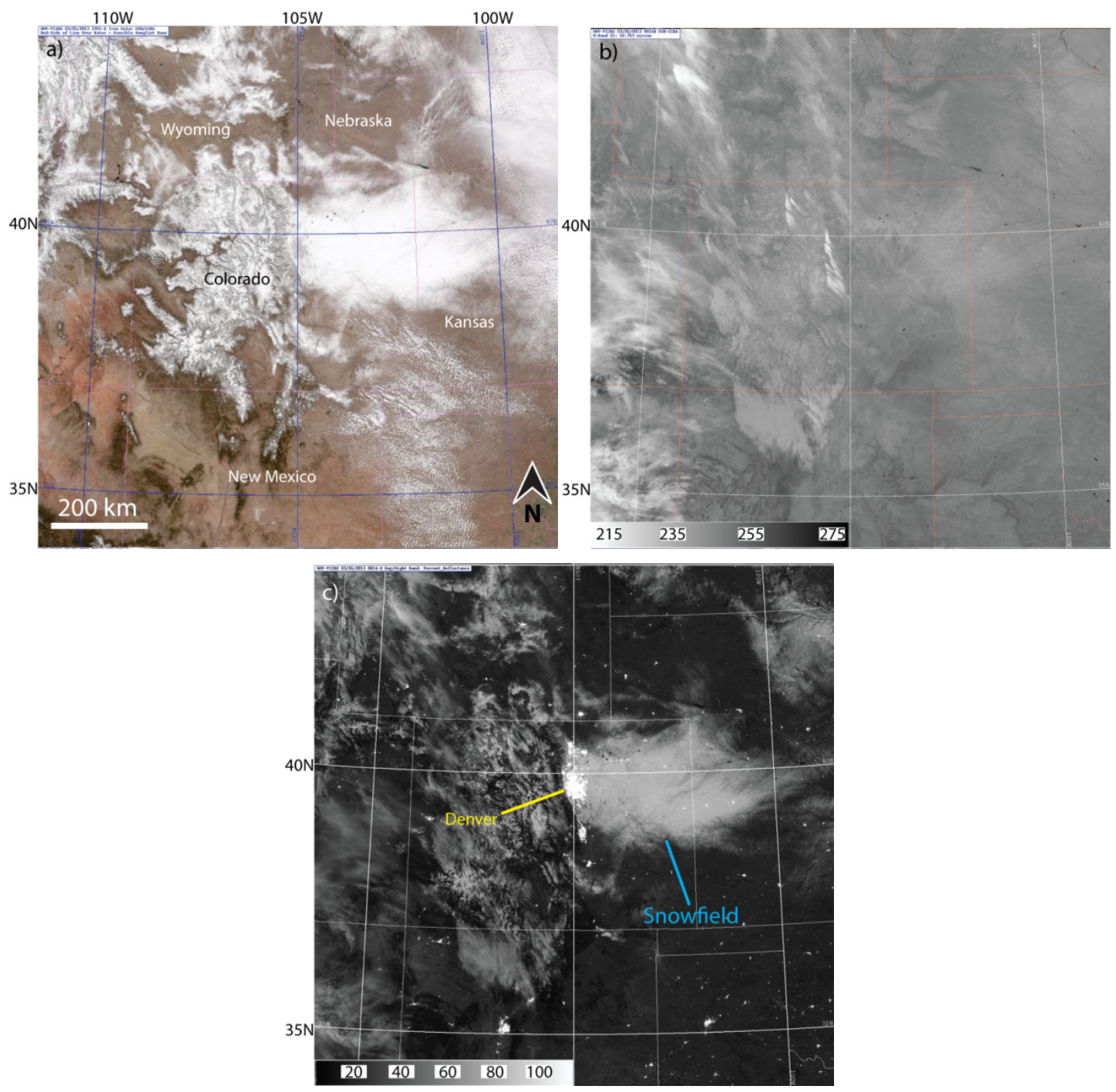

\subsubsection{Sea Ice Edge and Extent}

At high-latitudes, sea ice is a semi-permanent climatic feature [15] whose seasonal oscillations are monitored closely in the context of climate change assessment. Given this relevance, and the generally impractical nature of in situ monitoring, considerable research in satellite-based methods for sea ice mapping has been developed (e.g., [26,27]). These efforts are led by the National Snow and Ice Data Center (NSIDC), which provides an array of data sets derived from passive microwave, visible and thermal infrared sensors, and field observations (http://nsidc.org/data/seaice/). Operationally, there are many users of sea ice information, including supply vessels, oil and mineral extraction activities, and the crab fishing industry which typically operates very close to the ever-changing sea ice edge. The 
National Weather Service (NWS) Weather Forecast Office (WFO) in Anchorage, AK maintains an Ice Desk (http://pafc.arh.noaa.gov/ice.php) for real-time monitoring, issuing of advisories, and providing real-time support to fishing vessels in the Gulf of Alaska.

Figure 5 illustrates a particularly useful aspect of nighttime lunar reflectance for the purpose of sea ice detection in the event of cloud obscuration. Figure 5a shows a VIIRS M15 thermal infrared view of the Chukchi Sea, with brightness temperatures scaled to provide strong contrast between sea ice and open waters. Many fissures and leads (which play an important role in ocean/atmosphere moisture and heat exchange; e.g., [28]) are evident as dark features in the upper-right portion of the scene. A smooth/featureless region off the coast of Russia depicts an area of low/mid-level clouds that are optically thick to thermal infrared radiation, offering little insight on the presence of a detailed sea ice structure below them. In Figure 5b, DNB moonlight reflectance readily shows the sea ice details. The sea ice distribution is revealed by virtue of the more scattering nature of clouds at visible light wavelengths (e.g., [29]).

Figure 5. Comparison between (a) VIIRS/M15 thermal infrared imagery (kelvins) and (b) VIIRS/DNB lunar reflectance (\%) imagery of sea ice in the Chukchi Sea on 28 November 2012, 1505 UTC. The DNB lunar reflectance offers the unique ability to peer through semi-transparent clouds that are opaque at thermal infrared wavelengths, revealing the sea ice structures residing below them.

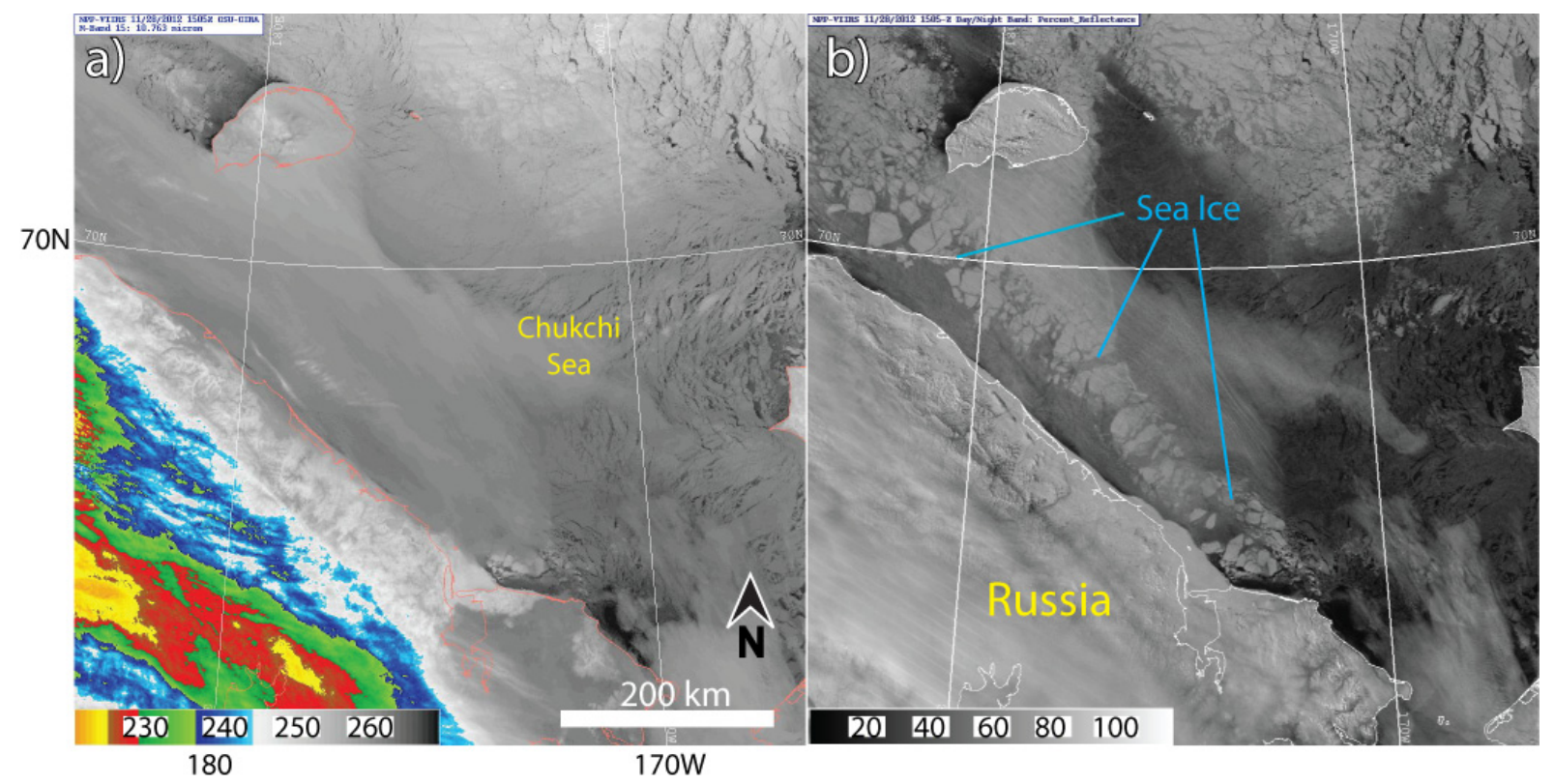

\subsection{The Hydrosphere}

The hydrosphere typically refers to water in all phases below, upon, and above the Earth's surface. For the purposes of this discussion, we will refer to the hydrosphere as the condensed but unfrozen liquid-water surfaces, including the world's oceans and fresh water reservoirs (both on and below the surface). Over two-thirds of the Earth's surface is covered by ocean, and air/sea interactions (e.g., exchange of heat, momentum, and water) play a critical role in defining our planet's weather and 
climate. Well-known phenomena such as El Nino, the Northern Atlantic Oscillation, and the Madden Julian Oscillation are all examples of strong ocean/atmosphere coupling. The ocean is optically thick to all VIIRS bands, and so information about the underlying circulation can only be inferred from surface measurements. Shown below are selected examples where moonlight reflectance provides such insight.

\subsubsection{Sea Surface Roughness Properties via Moon Glint}

In most visible satellite imagery, the ocean surface appears very dark due to its low albedo. However, the ocean surface reflectance increases rapidly in the region where near-specular (mirror) geometry occurs between the direct-beam illumination source (sun or moon) and the observer (satellite). This region is defined as the glint zone, whose appearance in polar-orbiting satellite imagery has been examined comprehensively via OLS imagery [30]. In contrast, most land surfaces produce negligible specular reflectance (with the exception of surfaces having considerable fractions of standing water, such as marshlands). The extent of the glint zone is a strong function of the ocean surface roughness, and hence, is dependent on surface wind speed and ocean surface properties [31]. The properties of the glint can therefore provide useful information about the near-surface wind conditions.

Within the glint region itself, water surface information akin to what would be provided by a bi-static radar system is possible. Surfactants such as bio-slick films (and oil slicks) suppress capillary waves in the sea surface microlayer (i.e., the top $\sim 1 \mathrm{~mm}$ of ocean surface; [32]). When these films occur in the glint zone, the sea surface currents responsible for their pooling/orientation can be inferred. Another phenomenon that manifests in surface roughness modulation is the internal solitary wave (solitons, or "waves of translation"; [33]). These waves, which travel between two layers of the ocean stratified by density, can extend for $10 \mathrm{~s}$ of $\mathrm{km}$ propagate unabated over very long distances. They are common to coastal regions and often are associated with tidal forcing, producing bands of smooth and roughened water as a shoreward-propagating wave train. The waves increase the surface roughness in areas where the horizontal flow converges, allowing for their view in the glint zone. Solitons have been observed via satellite imagery in the sun glint zone [34,35] - the DNB can now provide similar high spatial resolution views of solitons during the nighttime hours via moon glint in a way entirely analogous to daytime sun glint.

Figure 6 compares thermal infrared VIIRS imagery (M15) to DNB imagery for a southern portion of the Celebes Sea, located in the Indonesian archipelago. The Celebes Sea is characterized by complex bathymetry. Deep waters $(>4000 \mathrm{~m})$ transition rapidly to shallow waters associated with the surrounding land masses. The Mindanao current, which enters Celebes Sea from the east/northeast and produces a counter-clockwise flow within the basin, provides a strong interaction with the bathymetry, and the regular production of solitons. In this example, whereas the thermal infrared imagery (Figure 6a) provides strong sensitivity to the cloud field, it contains no information regarding the presence of solitons. In contrast, the favorable moon glint geometry of the DNB (Figure 6b) reveals a soliton train propagating toward the southeast. In this case, the roughening signature of horizontal convergent flow suppresses the otherwise strong glint signature in these otherwise calm waters. Similar analyses are possible during the daytime using sun glint, including applications to other water surface roughness features such as surface currents and ship wakes. It is worth noting that, unlike daytime sun-synchronous satellite observations of sun glint which vary only over annual cycles for a given 
region, nighttime lunar illumination angles (and the associated moon glint zone) change from one night to the next over the course of the lunar cycle - providing a broader regional sampling of glint-derived ocean surface properties.

Figure 6. (a) VIIRS M15 thermal infrared imagery (K) of the southern Celebes Sea (Indonesia) from 30 January 2013, 1723 UTC provides details on the cloud distribution, while (b) corresponding DNB lunar radiance imagery $\left(\mathrm{W} \cdot \mathrm{cm}^{-2} \cdot \mathrm{sr}^{-1}\right)$ reveals an internal solitary wave packet (appearing as dark curved lines) modulating the otherwise bright moon glint region.

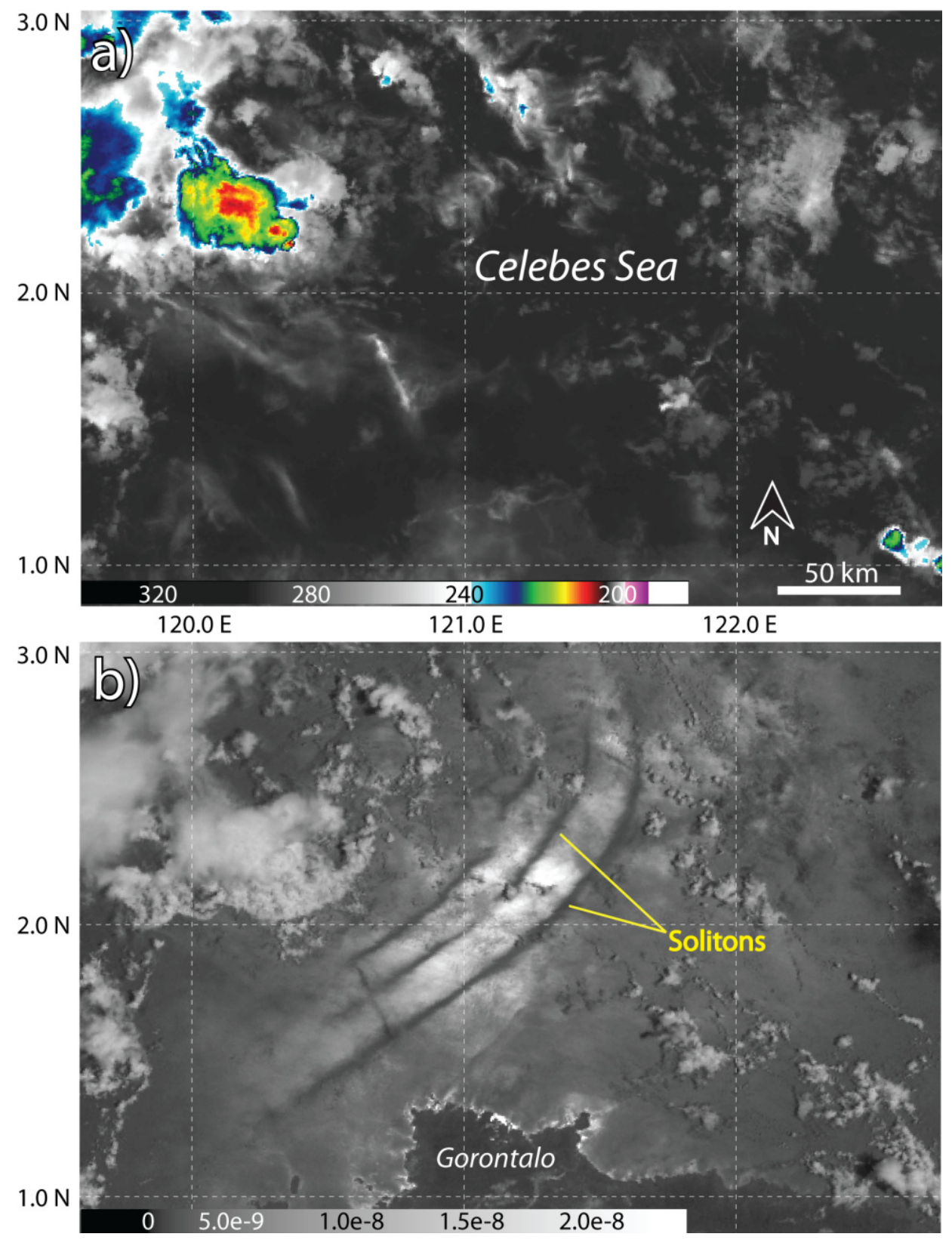


Figure 7. Timor Sea water turbidity observed by VIIRS in (a) daytime true color (27 June 2013, 0506 UTC), and the previous evening (26 June 2013, 1634 UTC) for the same coverage area via (b) thermal infrared (M15) imagery (K), and (c) corresponding DNB nighttime lunar reflectance (\%).

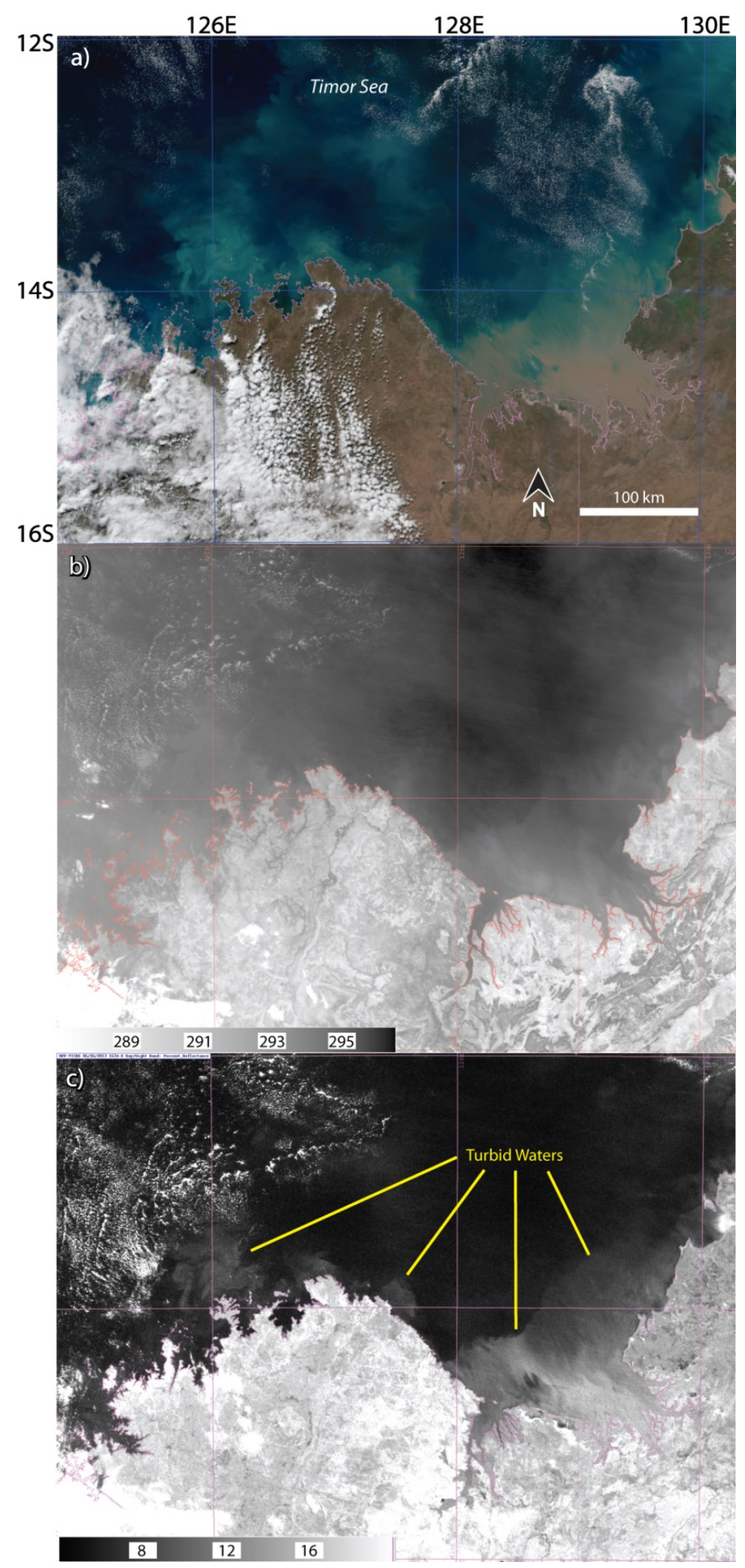




\subsubsection{Coastal Waters Turbidity}

VIIRS provides several shortwave bands designed to provide information on ocean color, building on high-quality products derived from the Sea-viewing Wide Field-of-view Sensor (SeaWiFS) and MODIS (e.g., [36,37]). These data provide critical insight into global ocean variability in the context of climate processes and ecosystem health (e.g., chlorophyll-a concentration related to primary productivity and parameters related to harmful algal blooms). These parameters and their relation to marine resources are important factors economically for littoral nations. Rivers deposit large amounts of sediments into the ocean, forming highly turbid regions which pose challenges to ocean color retrievals owing to significant contributions from the normally "dark water" near-infrared bands used for atmospheric correction (e.g., [38-40]). Currently, no observing systems are capable of producing ocean color products at night (including VIIRS). However, the DNB offers some insight on the nocturnal evolution of high turbidity features.

Figure 7 illustrates the utility of DNB moonlight reflectance to capture a subset of the highly reflective turbid waters in the Timor Sea off northern Australia. Here vast amounts of sediment-rich waters (estimated at a combined 173.2 tetralitres/yr flowing into the adjacent Timor and Arafura Seas; [41]) from a network of largely unregulated rivers which flow out to the sea. The alluvial materials, which include various nutrients and pollutants accumulated along the river catchments, support biological productivity in the coastal zone but occasionally cause eutrophication and fish death. The true color image (Figure 7a) reveals swirling sediment rich waters near the coast. In fact, the most turbid regions take on a similar coloration to the land surfaces. Comparisons between consecutive satellite overpasses can reveal details of plume motion. Figure $7 b, c$ compares the thermal infrared and DNB bands (both images scaled to show water features optimally). Despite variations in ocean emissivity and screening by overlying tropical water vapor, there is still a limited capacity to view sediment effects in the VIIRS M15 infrared band. However, the DNB lunar reflectance image shows the effect distinctly with far less ambiguity.

\subsection{The Lithosphere}

The lithosphere in the most general sense describes the outermost solid crust constituting Earth's surface. For the specific purposes of this discussion, we refer to the lithosphere in the context of the land surfaces observable by S-NPP. The lithosphere and atmosphere are closely coupled. While an argument could be made for inclusion of volcanic ash and lofted dust as being atmospheric parameters, they are fundamentally linked to the surface and so are included in this section. Similarly, the close coupling between the hydrosphere and the lithosphere presents a quagmire for categorizing a parameter such as soil moisture - included in the current section, perhaps for no better rationale other than the word "soil" coming first. In view of the full connectivity of the system, the well-grounded reader will appreciate that these somewhat arbitrary classifications are of secondary importance.

\subsubsection{Soil Moisture}

Visible light information can provide useful information about land surface conditions. The lower albedo of most vegetation compared to sparse/barren soil enables distinction of land cover types. 
Whereas the timescales of vegetation changes are such that daytime (conventional visible-based) monitoring is sufficient in most cases, supplementary nighttime information from the DNB can become useful in cases of rapid changes in vegetation state (such as burn scars or mudslides). In addition, information about the surface wetness can be inferred for some soil types. In the case of soil moisture assessment, most satellite-based techniques enlist passive microwave sensors (e.g., [42]), and while this offers a day/night capability, the spatial resolution of the lower frequency bands used for these retrievals (e.g., $74 \times 43 \mathrm{~km}$ sample footprint for the $6.9 \mathrm{GHz}$ band on the Advanced Microwave Scanning Radiometer-E; AMSR-E) means that any fine-scale details are lost.

Owing to the absorptive properties of liquid water at visible and near infrared wavelengths, the surface albedo of most vegetation-sparse soils decreases with increasing moisture content (e.g., [43]), and this behavior can exploited by DNB moonlight reflectance measurements. Figure 8 illustrates the concept of land surface albedo suppression in response to heavy rain over Kansas. In 2012, dry conditions stressed vegetation across the Great Plains - gradually increasing the surface albedo over wide expanses. On the night of 4-5 September 2012, a nocturnal complex of storms brought relief, with 1-2 inches of accumulation in some areas. Due to the convective-nature of this event, however, the distribution of rainfall was not uniform. Figure 8 a shows a radar-derived quantitative precipitation estimate (QPE) from the Multi-Radar Multi-Sensor System (MRMS; http://nmq.ou.edu/; e.g., [44]), with 12-hr rainfall accumulation. Figure 8b,c shows DNB lunar reflectance measurements of the pre- and post-storm nighttime scene, respectively. The dark striations observed in Figure 8c (further contrast-stretched to reveal detail) correspond roughly to the areas of significant radar-estimated rainfall accumulation (e.g., exceeding $\sim 0.5$ inches $(\sim 12.7 \mathrm{~mm})$, shown as green and warmer-color regions in Figure 8a). Such detail gleaned from differenced imagery may be useful in identifying changes to soil moisture in areas lacking radar coverage, and in confirming that radar-inferred precipitation indeed reached the surface (as opposed to virga).

\subsubsection{Volcanoes-Ash Plumes and Pyroclastic Flows}

Volcanic activity on Earth [45] is prolific, reminding us of the tremendous energy residing within the deep interior of our planet and the ever-changing configuration of the crustal (tectonic) plates drifting upon a molten core. Volcanoes tend to form at the interfaces between these plates, and the nature of the interfaces (e.g., divergent, convergent, slip, or in some cases mantle-plume hot spots such as the Hawaiian archipelago) determine the kinds of volcanoes produced. In terms of active volcanism, there have been approximately 1,300-1,500 Holocene epoch eruptions (dating back to $\sim 11,700$ years before present), with $\sim 20$ eruptions occurring at any given time worldwide. The Smithsonian Institute's Global Volcanism Program (www.volcano.si.edu) provides an excellent resource for monitoring volcanic activity. Volcanic ash poses notable hazards to aviation via a variety of damaging mechanisms as evidenced in power outages to commercial aircraft $[46,47]$. 
Figure 8. (a) Radar-derived precipitation 12-hr accumulation over Kansas from 4 September 2012, 2000 UTC to 5 September 2012, 0800 UTC, (b) DNB in-band radiances $\left(\mathrm{W} \cdot \mathrm{cm}^{-2} \cdot \mathrm{sr}^{-1}\right)$ from 3 September 2012, $0841 \mathrm{UTC}$, prior to the rainfall, and (c) corresponding DNB radiance imagery from 5 September 2012, 0803 UTC (end of radar accumulation period) showing darkened surface features in the wake of the storms, indicative of wet soil. The dark features correlate with the significant accumulation patterns shown in panel (a).
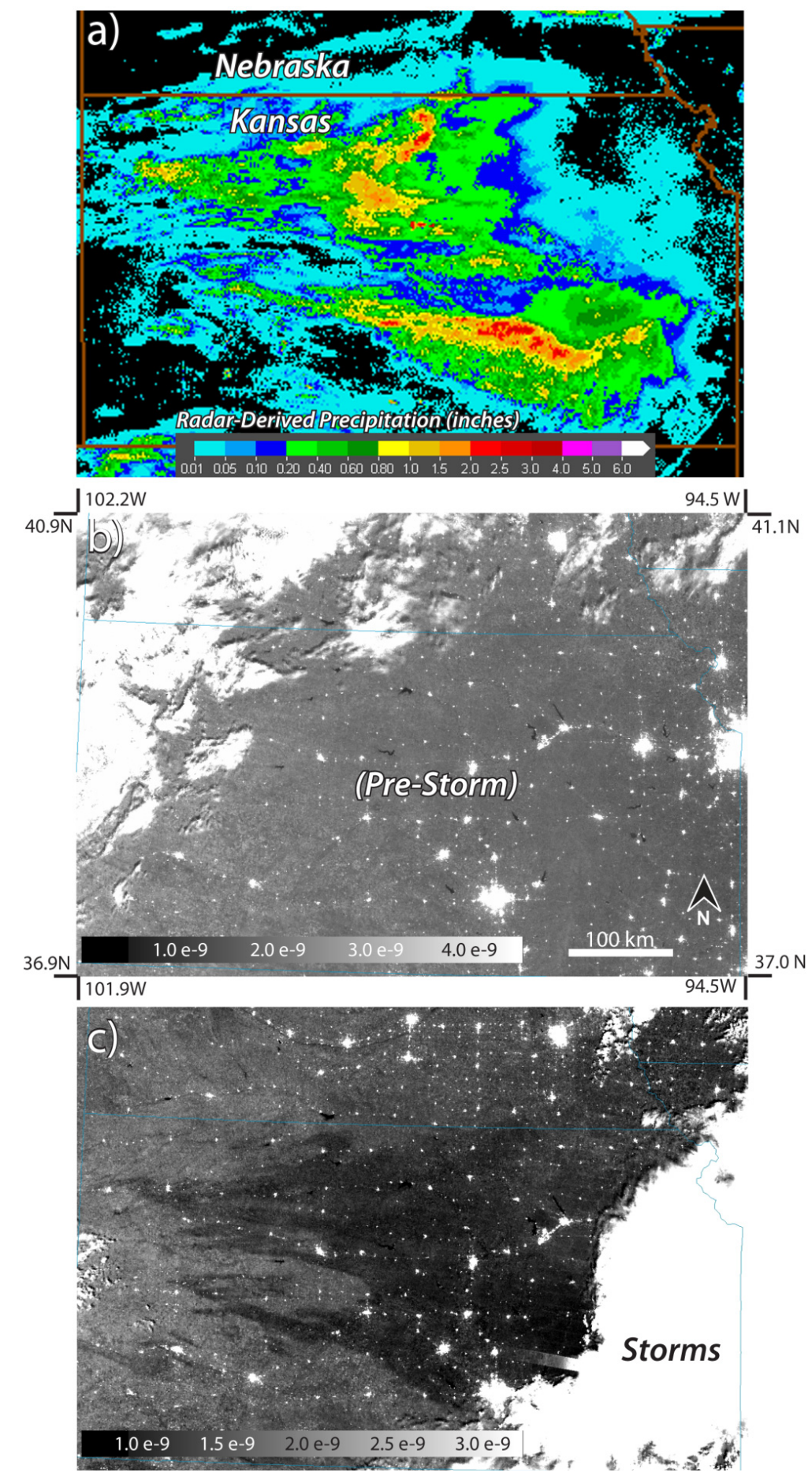
Awakening from its 116 year dormancy, the Tongariro volcano in New Zealand began erupting on 6 August 2012. The New Zealand GeoNet Project reported the detection of a new crater, and indication of lava bombs thrown 1-2 km from the Te Mari craters area. The eruption produced a significant eastward drifting ash plume, leading to road closures, the delay/cancellation of local flights, airport closures, and self-evacuations in the area. Figure 9 compares VIIRS thermal infrared measurements (Figure 9a) to DNB radiances (Figure 9b). In addition to improved detection of the low-level ash plume by reflected moonlight, the DNB-observed shadows provide a means for estimating plume height. Satellite-based detection and characterization of volcanic ash plumes has advanced considerably with multispectral satellite measurements (e.g., [48]). Nevertheless, the DNB may still provide useful supplementary observations, since plume composition can confound even sophisticated infrared algorithms.

Figure 9. (a) VIIRS M15 $(10.763 \mu \mathrm{m})$ Brightness Temperature image on 6 August 2012, 1252 UTC identifies the colder (higher/thicker) portions of an ash plume produced by the Tongariro Volcano in northern New Zealand. (b) Corresponding Day Night Band lunar radiance imagery $\left(\mathrm{W} \cdot \mathrm{cm}^{-2} \cdot \mathrm{sr}^{-1}\right)$ more readily reveals the full extent of the plume, including low-level ash closer to the volcano.

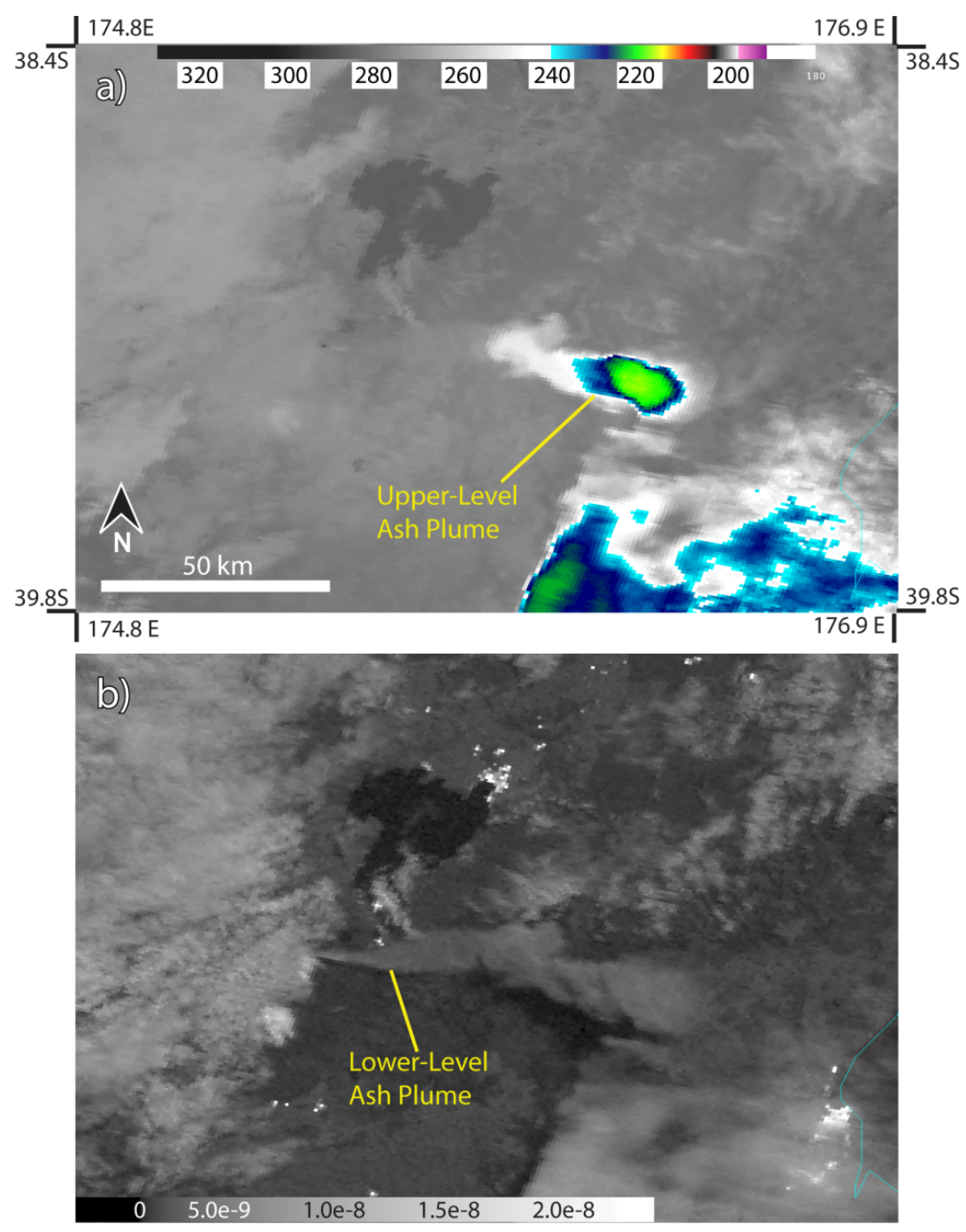


Most (>75\%) of the world's active and dormant volcanoes reside along the Circum-Pacific belt, also referred to as the "Pacific Ring of Fire." The Plosky Tolbachik volcano, located in Kamchatka, Russia, provides a recent example of how volcanic activity can be monitored at night with the DNB in a way that complements infrared-based (e.g., $[48,49]$ ) techniques. According to bulletins issued by the Tokyo Volcanic Ash Advisory Team (VAAC) and the Kamchatka Volcanic Eruption Response Team (KVERT), the volcano began erupting on 27 November 2012, producing lava from fissures on the western side of the massif that traveled $17-20 \mathrm{~km}$. Whereas the initial eruption produced ash to an altitude of 4-6 km, the ash production subsided dramatically thereafter, making this mostly a lava flow event [50]. Similar to its capacity over active fires, the DNB readily detects the light emissions from lava flows. Figure 10 compares high-resolution ( $\sim 30 \mathrm{~m})$ Advanced Land Imager (ALI) visible (Figure 10a) and near infrared (Figure 10b) imagery from the NASA Earth Observing One (EO-1) Mission against VIIRS/DNB nighttime imagery. The DNB image (Figure 10c) was scaled to match approximately the ALI coverage, and so its $742 \mathrm{~m}$ spatial resolution (high, by meteorological standards) appears relatively coarse here although it does capture the basic structure of the flow. Over volcanoes in overcast conditions (unlike the clear-sky example shown here), light emissions from lava will scatter through all but the most optically thick clouds, revealing the presence of these flows when thermal infrared bands would be obscured (based on the same principles illustrated for sub-cloud sea ice detection, discussed previously).

Figure 10. NASA Earth-Observing-1 (EO-1) Advanced Land Imager (ALI) visible (a) and near-infrared (b) high resolution $(\sim 30 \mathrm{~m}$ pixels) views of a pyroclastic flow on 1 December 2012, associated with the eruption of the Plosky Tolbachik volcano. VIIRS DNB radiance imagery on a moonless night (12 December 2012, 1547 UTC) matched to approximately the same location (c), shows visible light emission from the same feature. (EO-1 imagery courtesy of J. Allen, NASA Earth Observatory).

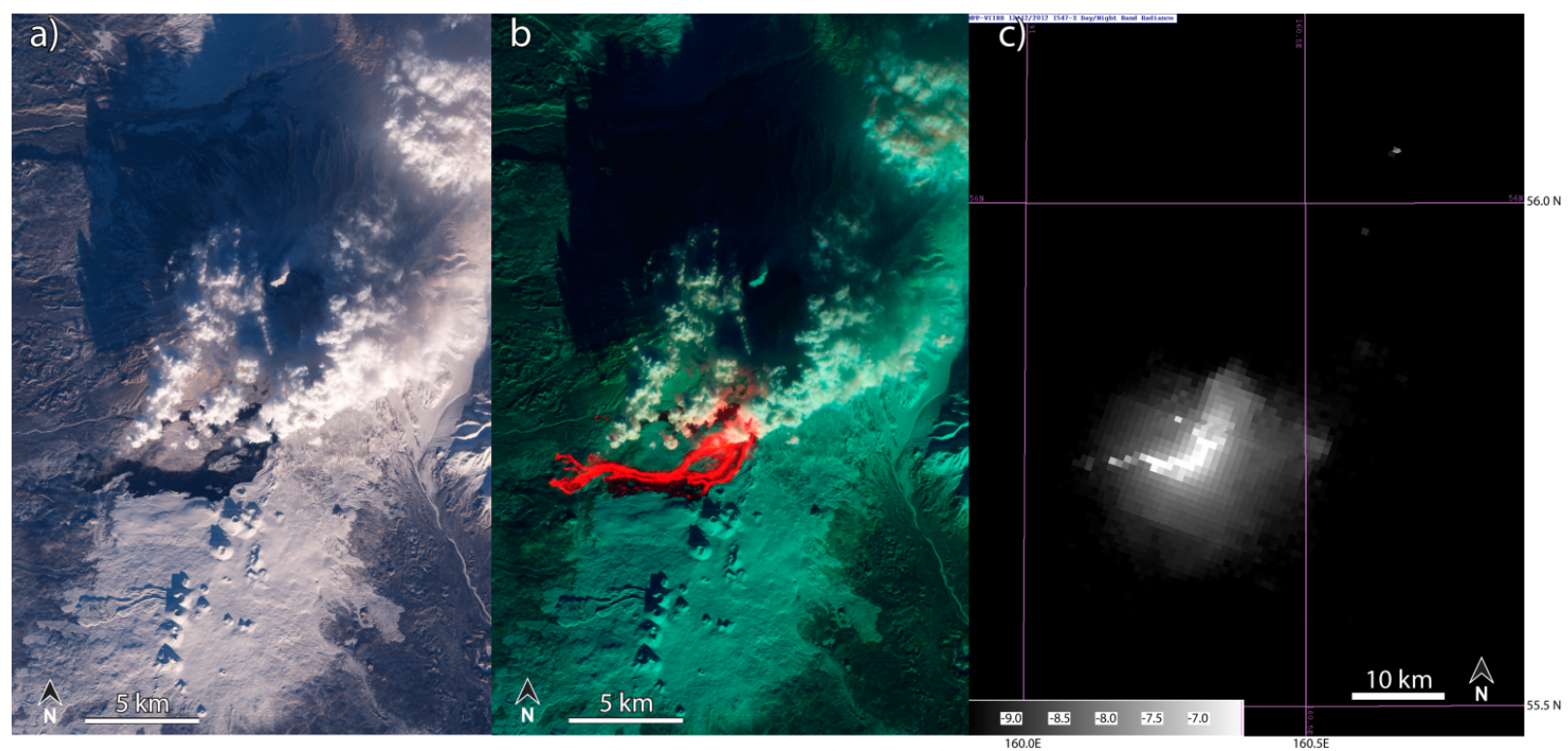




\subsubsection{Wind-Lofted Dust}

Mineral dust plays an integral role within the climate system. It alters the atmospheric and surface radiation balance via both direct and indirect processes, changes the nature of clouds and precipitation, affects surface hydrology via snow/ice albedo suppression, and provides iron-rich nutrients stimulating phytoplankton growth to both the oceans and rain forests. Dust can represent a hazard to humans in terms of its adverse impacts on air quality (respiratory health) and atmospheric visibility (e.g., aviation and surface-based travel). These impacts are not localized to the desert regions; lofted dust is transported globally [51]. Satellite-based multispectral methods are well suited to the dust detection problem (e.g., [52]) but can experience challenges at night, particularly when the dust is close to the surface.

Figure 11 shows a plume of dust lofted ahead of a frontal system over the eastern Mediterranean Sea on 9 April 2012 at 2315 UTC. Figure 11a (VIIRS M15 thermal infrared imagery) shows a general lack of sensitivity to low-altitude dust that is blowing offshore of Egypt and into the eastern Mediterranean Sea. On this evening, the moon was roughly two days past full (waning gibbous) and close to overhead at the time of the satellite overpass. The DNB imagery (Figure 11b) shows the dust as a diffuse plume, with lunar reflection providing good visual contrast over the dark ocean background. Visible contrast is low-to-nonexistent over the highly reflective desert surface of northern Egypt, although the presence of the dust layer can sometimes be inferred by attenuation and diffusion of the terrestrial light sources. Preliminary work related to the use of city light attenuation and diffusion to retrieve aerosol optical depth from DMSP/OLS [53] and more recently the DNB observations [54] promises to extend satellite-based quantitative aerosol property estimation to the nighttime hours.

Figure 11. (a) VIIRS/M15 thermal infrared imagery (K) on 9 April 2012, 2315 UTC offers weak contrast for low-level dust. (b) Corresponding DNB lunar reflectance imagery (\%) provides superior contrast, revealing the full extent of the lofted dust plume over the eastern Mediterranean Sea.
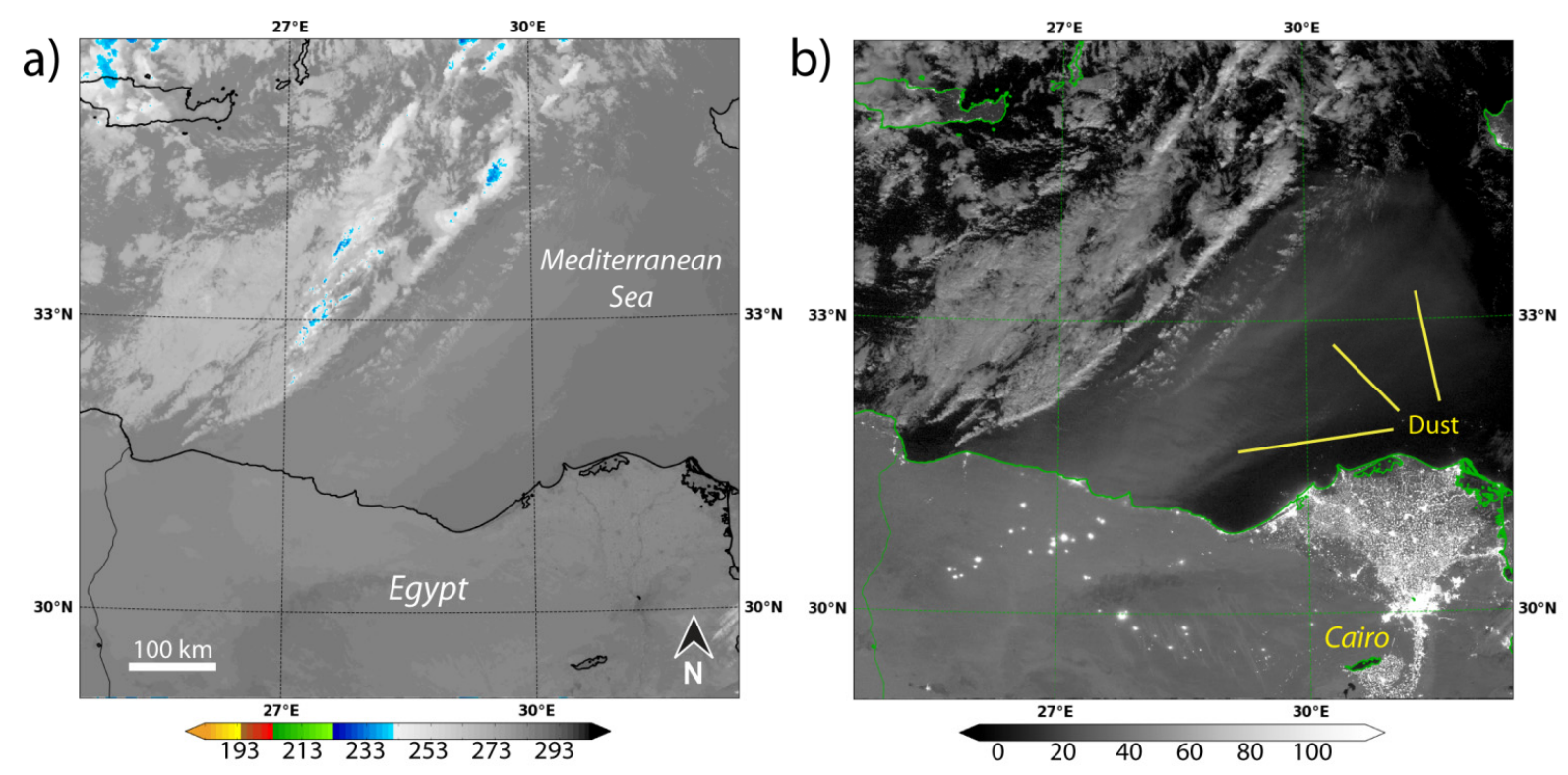


\subsection{The Atmosphere}

The origins of Earth's gaseous atmosphere, via volcanic and primitive mantle outgassing, stochastic impacts by comets and other large bodies, or other processes, is a lively area of scientific inquiry and debate (e.g., [55]). When viewed on-edge from the vantage point of space, the atmosphere appears as little more than a thin veil enshrouding the relatively massive planet. Yet occurring within the lowest $7-17 \mathrm{~km}$ of this $\sim 100 \mathrm{~km}$ deep layer, wherein $3 / 4$ of its total mass resides (defining the troposphere), is an almost unfathomable depth of complex processes that in concert account for an environment conducive to supporting life. The DNB now offers the potential to observe the diurnal cycle processes of atmospheric parameters whose characterization requires visible light measurements (e.g., cloud optical properties).

\subsubsection{Cloud Optical Properties}

Clouds play a key role in Earth's energy budget, acting as a regulator to both incoming solar radiation and outgoing thermal radiation. The widespread, semi-persistent clouds associated with the stratocumulus-topped boundary layer (e.g., [56]) in the subtropics are particularly important in this regard. Deficiencies and challenges in the representation of these clouds within numerical weather prediction models are well-identified (e.g., [57-59]) and stand in the way of substantial forecast improvements with regard to both global and regional climate change. In this regard, perhaps one of the most important meteorological advances enabled by the calibrated DNB observations pertains to improved cloud detection and diurnal cloud optical property information.

Figure 12 shows a sequence of cloud optical depth retrievals for a field of marine stratocumulus clouds off the California coast. Daytime retrievals from GOES for the late afternoon of 25 April 2013 (Figure 12a; 1630 local time, or 26 April 2013, 0030 UTC) and the following morning (Figure 12d; 0830 local) utilize the Daytime Cloud Optical and Microphysical Properties (DCOMP) algorithm outlined in [60]. The center two panels compare nighttime cloud optical depth retrievals for the same region based on an adaptation of the DCOMP to accommodate DNB lunar reflectance measurements (Figure 12b; [61]) and the experimental Shortwave-infrared Infrared Split-window Technique (SIST) GOES-15 (Figure 12c; [62]). Peak visible optical depths in the late afternoon are in the range of 40-60, and significantly higher in the morning image. The trend is consistent with those noted from field program data such as the First International Satellite Cloud Climatology Project (ISCCP) Regional Experiment I (FIRE I; [63]), with a minimum in the mid-afternoon and maximum just prior to sunrise. The DNB retrievals confirm the trend toward optically thicker clouds at night, whereas the SIST retrieval lacks sensitivity to clouds with visible optical depths larger than $\sim 10$ due to saturation of the infrared signals.

\subsubsection{Lightning}

Lightning produced by electrified storm clouds is perhaps one of the most recognizable sources of atmospheric light emission. The direct human hazards associated with cloud-to-ground lightning are well understood, and the more common inter/intra-cloud flashes [64] can damage electronic equipment on aviation and space launch craft [65]. Indirectly, the presence of lightning is an indicator of intense 
convection and the associated aviation hazards of in-cloud and clear-air turbulence, strong speed and directional wind shear (including microbursts), large hail and super-cooled liquid water droplets, and reduced visibility. In terms of forecasting, changes in lightning density and flash rate have proven useful for issuing severe thunderstorm and tornado warnings [66], and the presence of lightning has been used as a basis for modifying environmental state properties of numerical weather prediction models leading to more accurate simulations (e.g., $[67,68]$ ).

Figure 12. Imagery sequence of marine stratocumulus optical depth retrievals off the California coast for (a) GOES-15 late afternoon (25 April 2013, 1630 local), (b) VIIRS DNB nighttime pass (26 April 2013, 0130 local), (c) corresponding infrared-based GOES-15 nighttime retrieval, and (d) GOES-15 early morning (26 April 2013, 0830 local). (Nighttime GOES-15 example courtesy of Pat Minnis, NASA Langley Research Center).
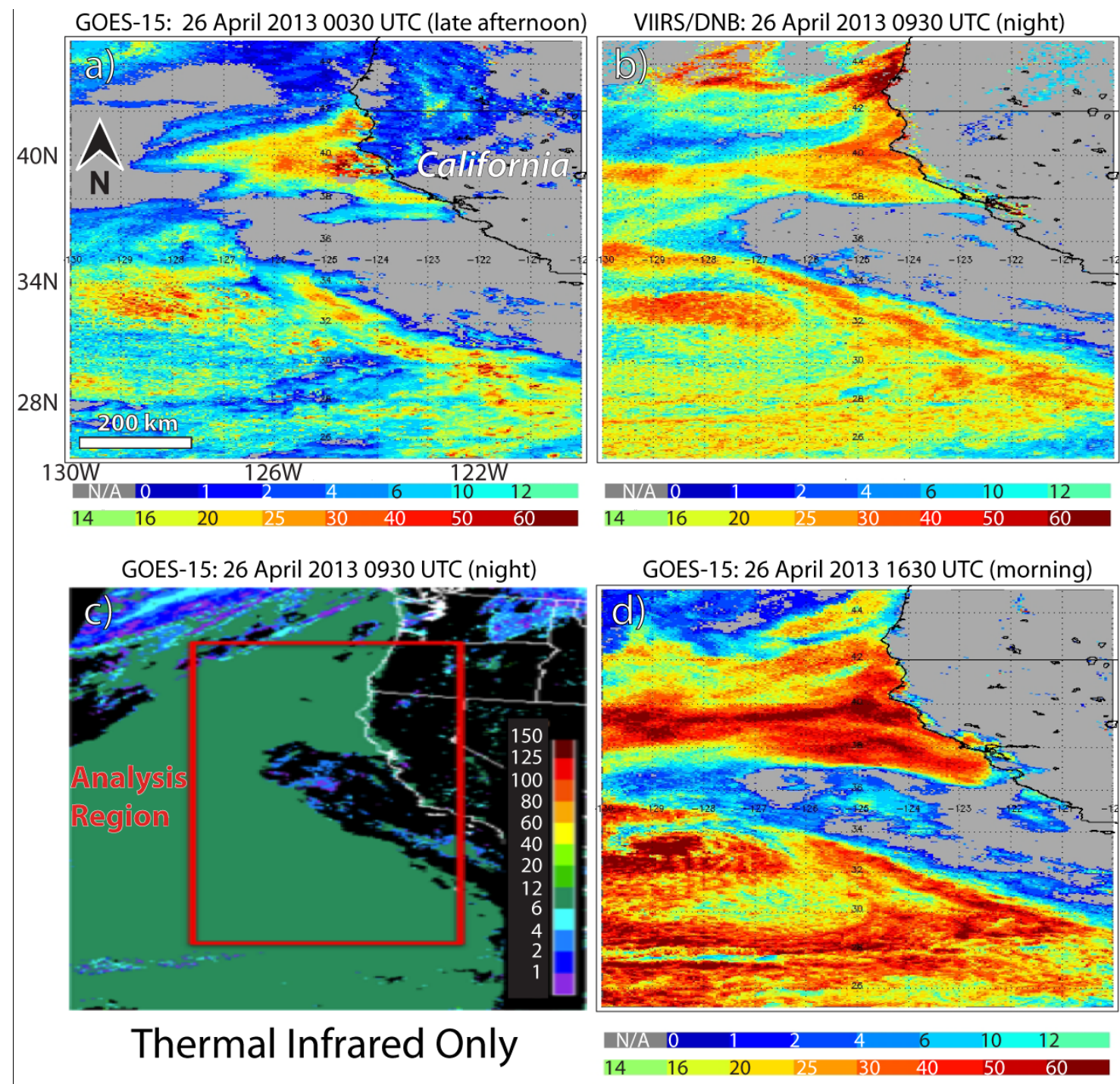

Thermal Infrared Only

While the DNB can detect the diffused light emerging at cloud top associated with nearby lightning flashes, it is not designed for this purpose and interpretation is non-trivial. As a traditional scanning imager, it does not offer a dwell capability like the Lightning Imaging Sensor (LIS) on the TRMM 
satellite, or true staring sensors that will be on future geostationary satellites such as the GOES Lightning Mapper (GLM). As a result, the DNB will not detect most lightning flashes. However, depending on the lightning flash rate of a storm, and given typical flash durations of $10 \mathrm{~s}$ of ms or more [69], there is a chance that the DNB will capture the in-cloud scattered light from these transient emissions. Similar to their detection by the DMSP/OLS (e.g., [70]), lightning flashes manifest in DNB imagery as short along-scan segments $(\sim 12 \mathrm{~km}$ wide strips formed by 16 adjacent simultaneously observed scan lines), with variable horizontal extent depending on flash duration and the degree of light diffusion (multiple scatter within the cloud). Figure 13 illustrates how lightning flashes manifest in DNB imagery, for a line of convection over Louisiana (Figure 13a). Here, low elevation angle moonlight provides high-relief storm-top detail - revealing turrets associated with the convective cores as well as cloud-top gravity wave structures. Adjacent scans, separated in time by $\sim 1.8 \mathrm{~s}$, would typically observe different flash events (again, due to typical flash events being of order $\sim 10 \mathrm{~ms}$ ), resulting in along-track discontinuities in DNB imagery over nocturnal thunderstorms. In some cases, flashes from a thunderstorm far-removed from the current scan location may be "detected"; here, the horizontal light transport from the distant flashing cloud illuminates clouds or surface at the current scan location for the duration of the remote flash sequence, producing segments of brighter local features that are similar in appearance to the bright segments observed atop the actively flashing storms themselves.

Figure 13. Lightning flashes atop a nocturnal squall line crossing over Louisiana on 4 Apr 2012, 0752 UTC appear in DNB radiance imagery $\left(\log _{10}\left[\mathrm{~W} \cdot \mathrm{cm}^{-2} \cdot \mathrm{sr}^{-1}\right]\right)$ as bright streaks aligned with the sensor scan lines.

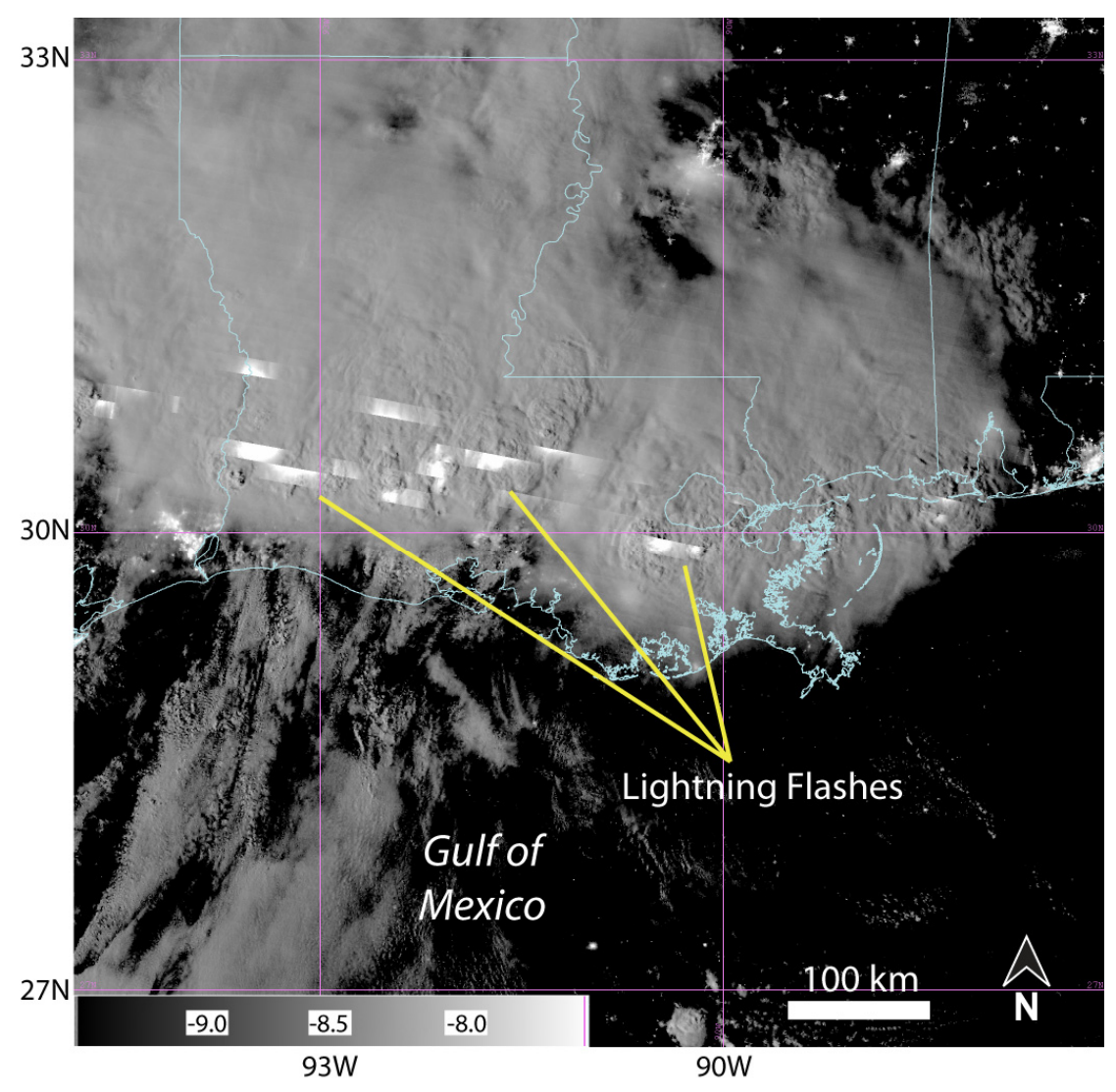




\subsubsection{Tropical Cyclones-Exposed Low-Level Circulation}

Storms forming in the energy-rich tropical oceans can, under favorable conditions, organize to form one of Nature's most violent and destructive weather systems: the tropical cyclone. In their most powerful stages, as Category 5 storms on the Saffir-Simpson scale, hurricanes (as they are called in the Atlantic and eastern Pacific) and typhoons (in the western Pacific and Indian Ocean) pose a significant threat to coastal communities in the forms of sustained winds exceeding $250 \mathrm{~km} / \mathrm{h}(155 \mathrm{miles} / \mathrm{h})$, torrential rainfall and inundating pressure and wind-driven storm surges. Hurricane Katrina produced a surge of more than $12 \mathrm{~m}$ in some parts of coastal Mississippi. It is no wonder that so many resources in the form of monitoring centers (e.g., the National Hurricane Center in Miami, FL, and the Joint Typhoon Warning Center in Honolulu, HI), observations (NOAA P-3 flights, and satellite missions such as the Tropical Rainfall Measurement Mission (TRMM; [71]) and the upcoming Cyclone Global Navigation Satellite System (CYGNSS; [72])), and models (e.g., the Hurricane Weather Research and Forecast model) are dedicated to around-the-clock monitoring and prediction of these storms.

There are many aspects of tropical storm monitoring that may benefit from low-light visible observations, from organization as a tropical depression, through the mature stage and ultimately landfall or extra-tropical transition. Lunar reflection-based observations of low-level circulation, cloud top structure (overshooting tops indicative of convective hot-tower activity), and inner-eye-wall low cloud vortices can in some cases improve upon the detail available from thermal infrared observations. Even the detection of eye-wall lightning for remote storms (where resources such as the World Wide Lightning Locator Network may lose accuracy in detection/location of all strikes) can provide indicators of ensuing storm intensification. Low-light visible imagery can even be useful in assessing the aftermath of tropical cyclones (and other natural disasters) by indicating the locations of power outages through comparison of pre- and post-disaster city light imagery ([73]; and Section 3.5.1 below).

Round the clock storm tracking is critical for short term forecasts of track and intensity. Satellite-based methods (e.g., [74,75]) are best equipped to provide continuous monitoring, and lowlight visible imagery provides an enhancement to nighttime capabilities. Figure 14 chronicles the dissipation of Hurricane Nadine over the course of three consecutive nights, and the power of low-light visible information in tracking the storm during this process. The top row of panels (Figure 14a-c) contains standard infrared imagery, while the lower row (Figure 14d-f) incorporates DNB moonlight reflectance along with VIIRS M15 thermal infrared imagery to reveal low/warm and highly reflective water clouds in yellow and cold upper-level ice clouds (associated with Nadine's deep convection) in white (optically thick) or blue (optically thin). Whereas the center of circulation is well defined initially, environmental shear disrupts storm organization and by the third night all that remains is the low-level circulation - almost completely indiscernible via thermal infrared imagery but easily seen with the addition of low-light visible information. Winds associated with these reduced-intensity systems can still exceed gale force and pose hazards to maritime vessels. As with many tropical systems Nadine meandered through the central Atlantic, with episodes of re-intensification, before ultimately dissipating. The ability of the DNB to reveal low-level circulation via moonlight reflectance provides forecasters with an additional useful tool in accurately tracking and monitoring the development of these systems through the nighttime hours. 
Figure 14. (a-c) VIIRS/M15 thermal infrared imagery (K) sequence from 2 to 4 October 2012 of Hurricane Nadine's dissipation over the central Atlantic Ocean; showing the evolution from a relatively well-defined eye in (a) to an asymmetric convection pattern in (b) due to increasing wind shear, and ultimately complete dissociation of the upper level circulation in (c). (d-f) Corresponding VIIRS/DNB and M15 false-color composite imagery, with lower-level clouds shown in yellow and upper-level clouds in blue/white, provides superior tracking of the low-level circulation pattern, particularly in the latter stages.

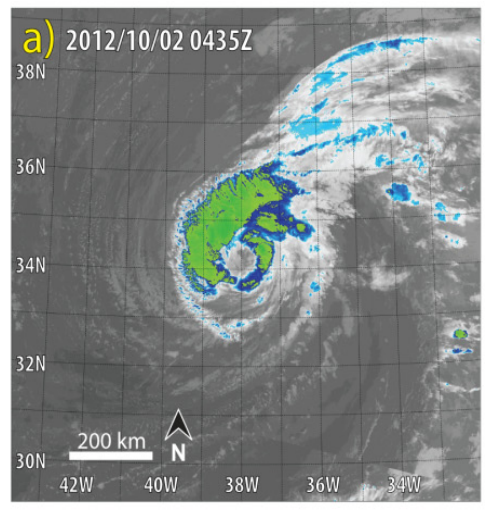

$\begin{array}{llllll}193 & 213 & 233 & 253 & 273 & 293\end{array}$

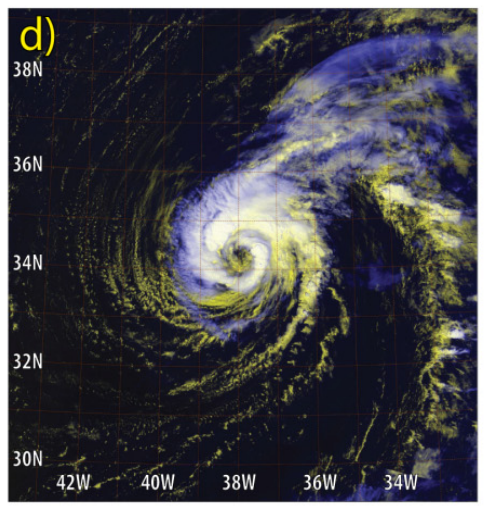

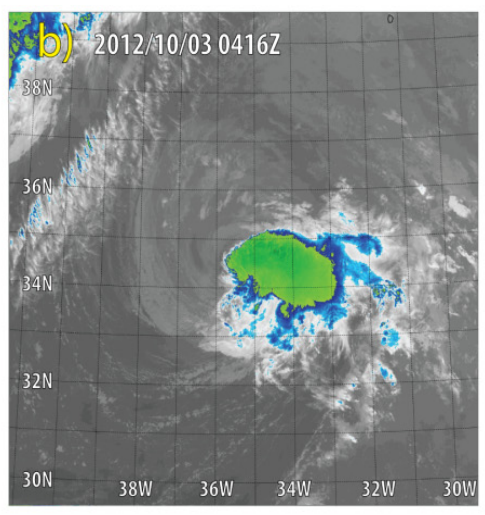

$\begin{array}{llllll}193 & 213 & 233 & 253 & 273 \quad 293\end{array}$

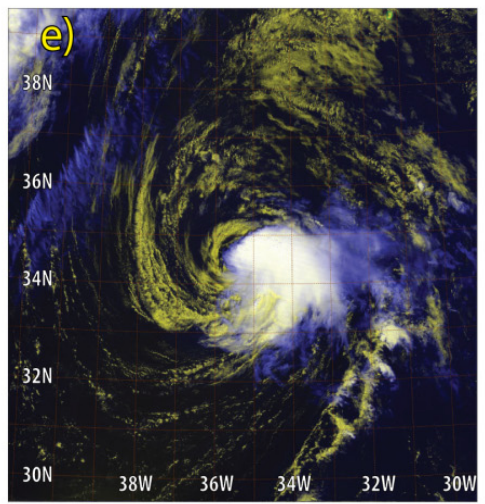

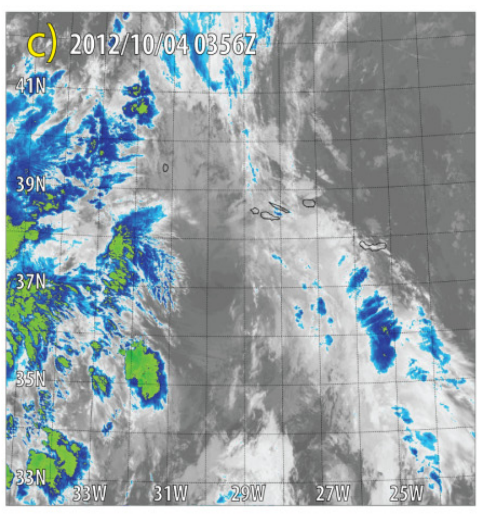

$\begin{array}{llllll}193 & 213 & 233 & 253 & 273 & 293\end{array}$

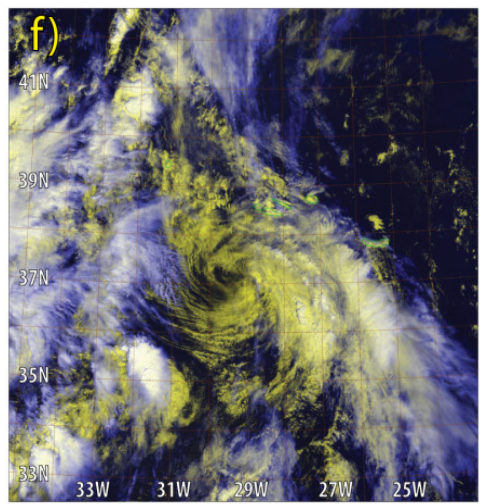

\subsection{The Biosphere}

The biosphere consists of all the living components of Earth's global ecosystem, both land and sea-dwelling, ranging in scale from microorganisms to continental-scale tropical and boreal forests. As inherent members of this system, we naturally regard the biosphere as the focal point of the climate system - in terms of how this sphere is impacted by changes occurring in the other components of the system. However, we need look no further than human-driven deforestation and carbon dioxide emissions to appreciate the reciprocal interactions of the biosphere and the climate system. Feedbacks among processes occurring within the biosphere, such as carbon dioxide sequestration by plants and production of oxygen, speak to the essential role of this system in the carbon cycle in maintaining an environment capable of supporting life. As illustrated in the examples to follow, the DNB offers unique capabilities for biosphere monitoring, including perhaps the most direct and readily recognizable measurements of human activity. 
Figure 15. Examples of before/after difference false color composite VIIRS/DNB imagery for (a) widespread coastal power outages associated with the landfall of Super Storm Sandy collected on 1 November 2012, 0653 UTC (using 25 September 2012, 0646 UTC pre-outage clear-sky reference imagery), and (b) a linear swath of power outages associated with a large tornado that struck southern portions of Moore, OK collected on 21 May 2013, 0727 UTC (using 20 May 2013, 0748 UTC pre-outage clear-sky reference imagery).

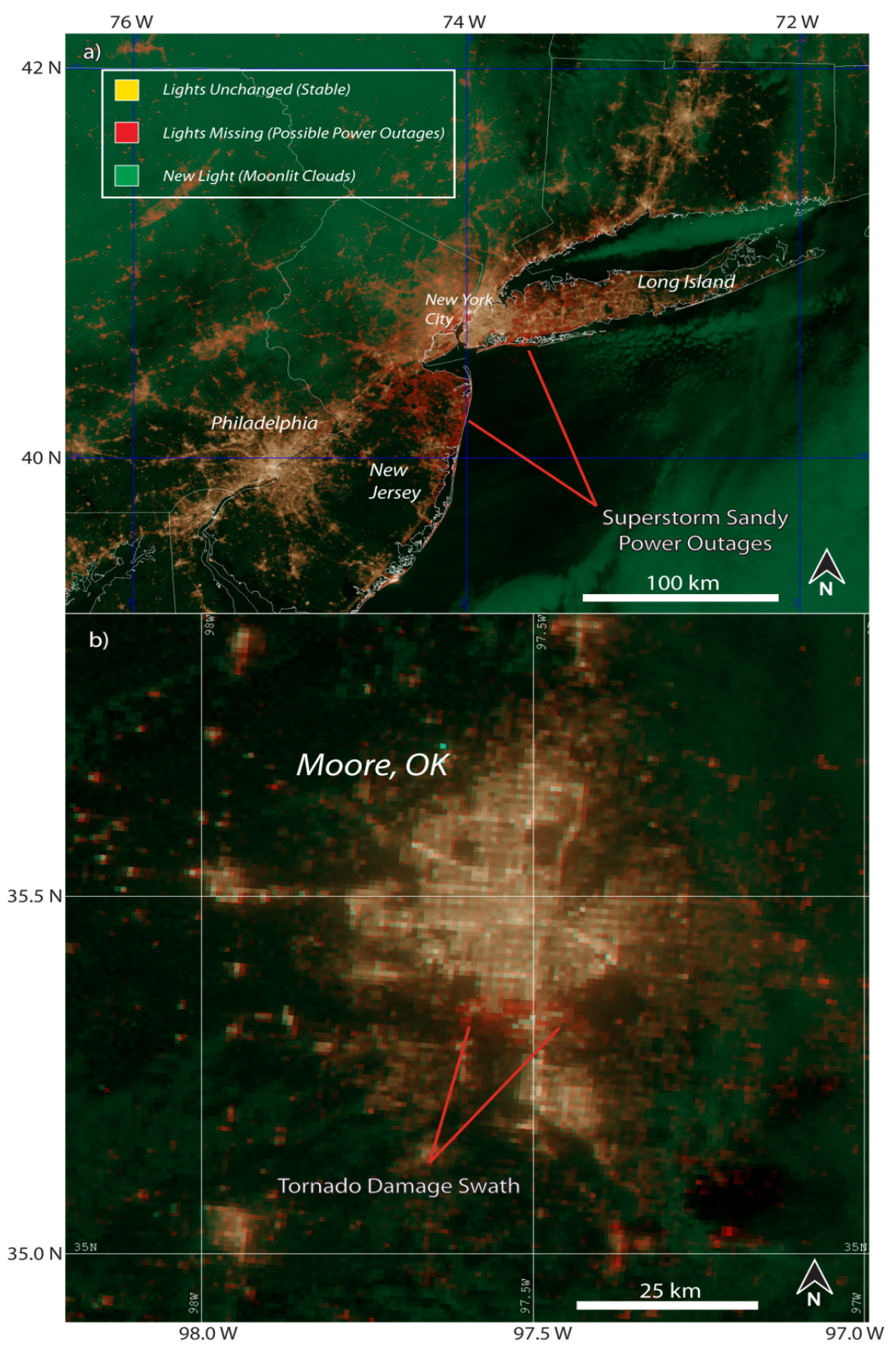

\subsubsection{City Lights and Power Outages}

Like the OLS before it, the DNB has ability to observe human settlements globally via artificial (anthropogenic) light detection. On moonless nights, discrete light sources from roadways, towns, and 
cities stand out prominently amidst the surrounding darkness. Iconic images of the nighttime lights of the world have in many ways transcended the science, uniquely revealing the 'human footprint' on Earth. As described in Section 2 (and Table 2), the DNB improvements have expanded the utility of low-light visible observations significantly, revealing the spatial distribution and intensity variations of these lights. Although peak urban lighting occurs typically in the early evening (before 10 PM local time; [6]), the DNB reveals that a considerable level of lighting remains even at the 1:30 AM overpass time. Since these light emissions remain more or less stable at the spatial scale of the DNB from one night to the next, a sudden and dramatic change can often be linked to power outages via "before vs. after" imagery.

Satellite imagery holds high value for assessing post-disaster impacts (e.g., [76]), and low-light visible sensing can play a particularly important role. Figure 15 depicts two notable recent examples of power outages associated with natural disasters (in the aftermath of Super Storm Sandy in Figure 15a, and the Moore, Oklahoma tornado in Figure 15b) — reminders of the coupling between the atmosphere, hydrosphere, and biosphere - that were captured by comparing before/after imagery from the VIIRS/DNB. The examples are presented in the form of false color composite imagery, where a scene prior to the outage ("baseline") is compared against a co-registered scene from after the outage. The information is encoded in such a way so as to produce red tonality in regions where bright lights existed in the baseline imagery but are not present in the "after" imagery. These red pixels, when they occur in the absence of cloud cover, are interpreted as power outages. Golden tonality corresponds to unchanged light emissions between the two times, and green tonality corresponds to regions where the "after" scene is brighter than the baseline. These green pixels may correspond to either the presence of moonlight reflecting clouds in the "after" scene, or in some cases to valid new lights corresponding, e.g., to search and rescue operations or triage stations established by emergency managers in wake of a natural disaster.

Low-light visible readily senses the emissions from natural gas flaring activity in the many petroleum producing regions (e.g., [77,78]). The practice of flaring, done to dispose of natural gas when infrastructure does not exist to harvest it, wastes energy but is a better alternative to venting the strong greenhouse gases (without combustion) directly into the atmosphere. However, it has become increasingly controversial due to the remaining large carbon dioxide emissions and pollutants released into the atmosphere. While most of the rigs flare constantly as part of their normal operations, their variation (e.g., the occasional need to relieve excess pressure results in larger flares) can be discerned by comparing the intensity of a light source from previous clear-sky nighttime overpasses. Notable examples include the Bakken Formation in North Dakota, the Eagle Ridge formation in southern Texas, offshore platforms in the Gulf of Mexico, and the oil fields of southern Iraq and Kuwait. Figure 16 shows a comparison between conventional $3.7 \mu \mathrm{m}$ imagery (VIIRS M12 band; Figure 16a) and a multi-spectral composite involving the DNB (Figure 16b). In Figure 16a, pixels with brightness temperatures exceeding $295 \mathrm{~K}$ have been colored in red. In order to help discriminate between the visible light emitted by the flares and those produced by electric lights associated with the infrastructure (i.e., camps and facilities) in Figure 16b, the VIIRS M10 (1.61 $\mu \mathrm{m})$ band, sensitive at night only to extremely hot emissions (up to $3000^{\circ} \mathrm{C}$ ) characteristic of natural gas flares, was enlisted to highlight locations of confident flaring in red. The global distribution of electrical lights themselves also provides valuable insight to greenhouse gas emissions. The natural correlation between the 
consumption of electricity and fossil fuel emissions attendant to the production of that electricity have prompted the use of nighttime visible data to detect, monitor and even quantify source regions for anthropogenic $\mathrm{CO}_{2}$ emissions (e.g., [79]).

Figure 16. (a) It is difficult to pick out the few isolated red pixels (noted by yellow circles) in this VIIRS M12 imagery (3.7 $\mu \mathrm{m}$; K) from 3 September 2012, 0839 UTC corresponding to hot-spots $(>295 \mathrm{~K})$ of natural gas flares associated with oil mining activities in the Bakken Shale Formation of North Dakota. (b) Corresponding VIIRS DNB radiance imagery $\left(\log _{10}\left[\mathrm{~W} \cdot \mathrm{cm}^{-2} \cdot \mathrm{sr}^{-1}\right]\right)$ show the broad expanse of lights from these flares as well as the surrounding human camps. Those flares producing sufficient thermal radiation to enable their detection by the M10 band $(1.61 \mu \mathrm{m})$ are enhanced in red.

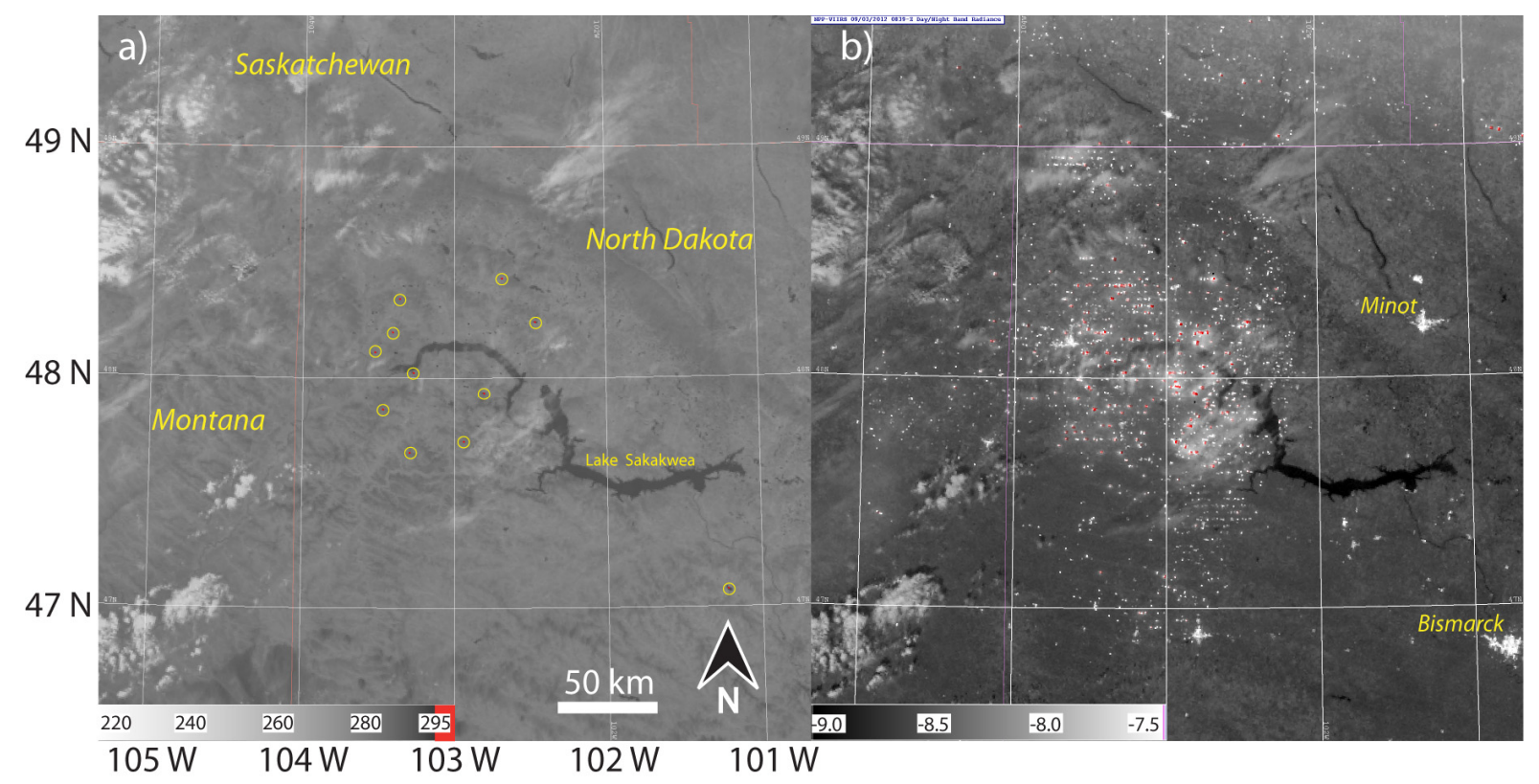

\subsubsection{Ship Lights}

As demonstrated previously via the OLS (e.g., [80]), maritime vessels (when lit) can appear as point sources in DNB imagery. Unlike city lights whose locations are fixed from one night to the next, ship lights typically are ephemeral. These lights can be found most often near coastal cities, but DNB examples of remote sources such as ice breakers in the Arctic and at the heads of ship tracks (clouds modified by ship effluents; e.g., [81]) have been noted. Occasionally these ephemeral light patterns appear to organize into cluster patterns. In some examples, the light patterns correlate with political boundaries drawn by the 1997 Sino-Japanese, 2000 Sino-South Korean, and 1998 Japanese-South Korean Agreements. Tracking the activity of ship lights in the vicinity of buoy moorings can also assist in the remote monitoring of vandalism and theft of these assets.

Perhaps the most prolific ship light activity occurs in the Sea of Japan and East China Sea - each ship producing a distinct point of light from the flood lamps used to attract squid to the surface. Here, large fleets of squid boats form coherent patterns that sometimes can be tracked from one night to the next. Figure 17 shows a false color composite "before/after" image using the same technique 
illustrated in Figure 15, highlighting the squid boat activity in the Sea of Japan. In this case, the changing lights correspond to the movement of ships, with red lights denoting where the boats were located on the evening of 24 September 2012 ( 1715 UTC) and green lights showing where they had moved on the following night. To the extent that the fishing fleets follow their catch, compositing imagery from multiple nights over the course of weeks, months, etc. can help to reveal seasonal patterns and variability in fish migration.

Figure 17. VIIRS DNB difference imagery of squid fishing boat fleets on adjacent nights (Night 1 = 24 September 2012, 1715 UTC; Night $2=25$ September 2012, 1656 UTC) in the Sea of Japan. Red and green pixels denote vessel movement from Night 1 to Night 2. Shown as inset photographs are examples of a fishing fleet and an individual ship adorned with booms of squid-attracting floodlights as seen from the surface.

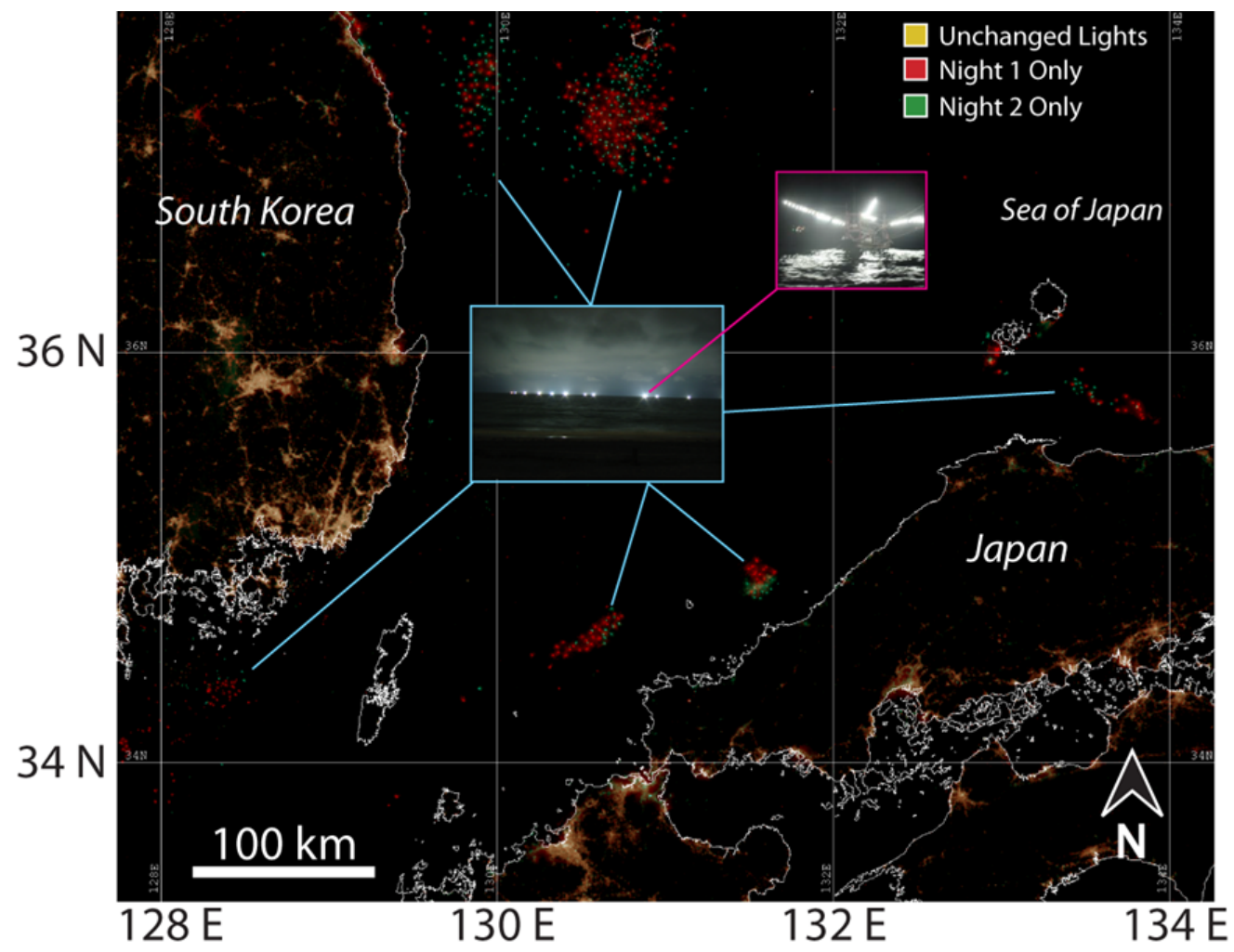

\subsubsection{Marine Bioluminescence}

Some members of the biosphere communicate through light emission, or bioluminescence. The most commonly recognized land-dwelling varieties include fireflies, glow worms, centipedes, and certain fungi such as mushrooms. A great number of marine organisms, including Anglerfish and Lanternfish; invertebrates such as jellies, coral, molluscs, and krill; and cephalopods such as squid and certain octupi, emit faint levels of visible-spectrum light for a variety of luring and repulsion purposes. By themselves, these luminous sources are far too small to be detectable by a spaceborne low-light visible sensor whose surface footprint is of order $1 \mathrm{~km}^{2}$. In large colonies, however, even the very smallest of organisms - bacteria, have been shown to produce a bioluminescent signal sufficient for satellite-based detection. 
The term "Milky Seas" describes a rare nocturnal phenomenon that occurs primarily in the northwestern Indian Ocean and the waters surrounding Indonesia [82]. Unlike the glowing waters sometimes observed in ship wakes or in breaking waves during "red tides", which are transient and highly localized light emissions produced by dinoflagellates in mechanically disturbed waters, the Milky Sea features a widespread, steady glow produced by luminous bacteria. In the most extreme cases, Milky Seas transform the usually dark nighttime water surface into something reminiscent of a snow field observed at mid-day. Incredible eye-witness accounts, describing these fields of glowing ocean extending to the horizon in all directions, casting light upon the bases of distant clouds, with luminosity sufficient to read a book by, have provided a source of inspiration for such famous marine adventure novels as 20,000 Leagues Under the Seas and Moby Dick.

Figure 18. (a) DMSP OLS detection of a bioluminescent Milky Sea on 25 June 1995; digitally enhanced imagery. Raw (digital counts) DMSP imagery for (b) 25 June 1995, 1836 UTC, (c) 26 June 1995, 1804 UTC, (d) 27 June 1995, 1725 UTC, and (e) 28 June 1995, 1841 UTC shows a persistent comma-shaped bright anomaly off the Somali coast.
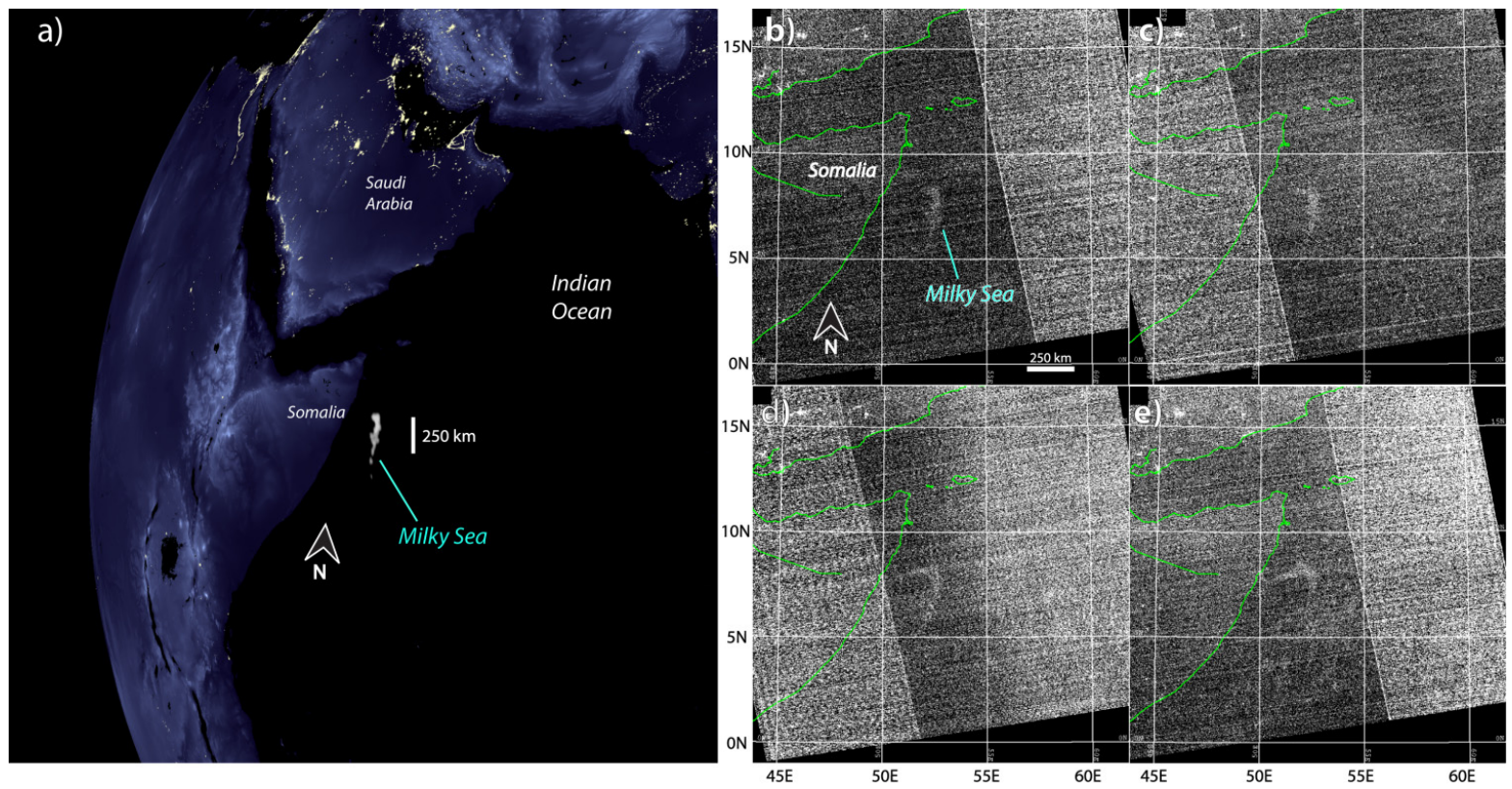

The broad spatial extent of Milky Seas affords the opportunity for satellite-based detection, provided the signal is strong enough and falls within the sensor's band pass. The DMSP/OLS captured a $15,000 \mathrm{~km}^{2}$ Milky Sea (Figure 18) that was reported by a British merchant vessel (S.S. Lima) off the coast of Somalia on 25 Jane 1995 [83]. The entry and exit locations derived from the ship were found to match precisely with a large comma-shaped emission feature whose "head" was found to be rotating counter-clockwise (Figure 18b-e) within a cool-water gyre-suggesting that this Milky Sea precipitated from the bacterial breakdown of a large phytoplankton bloom. It is the first known confirmation of a bioluminescent signal detected from the space platform.

At the time of this writing there have been no confirmed detections of a Milky Sea or any other bioluminescent signal (e.g., ship wakes) from the S-NPP VIIRS/DNB. While is too early to draw conclusions given the inherently rare nature of these events, the sensor in its current form may not be 
able to detect a Milky Sea due to the relatively poor overlap of its spectral band pass with the narrow cyan/green bacterial emission lines. This is in contrast to the more favorable spectral band pass of the OLS (discussed in [83]). Nonetheless, previously established confirmation of the detectability of a Milky Sea from space warrants mention in this survey of biosphere light signals. Most importantly, it provides an important example of how nocturnal visible light information opens doors to new frontiers of scientific inquiry. Future low-light visible satellite sensors, tuned to provide optimal sensitivity to the bioluminescent emissions, may one day provide the next research advance in this area.

\subsubsection{Biomass Burning}

Observations of fires from both geostationary and polar orbiting satellites have been used extensively for disaster and resource management, air quality applications, ecosystem and carbon cycle monitoring, climate studies and other purposes. Detection and characterization of heat sources has traditionally been limited to a combination of longwave $(11.0 \mu \mathrm{m})$ and shortwave IR channels $(1.6 \mu \mathrm{m}$, and $3.9 \mu \mathrm{m})$. Thermal infrared techniques by themselves cannot reveal whether a fire is actively flaming or just smoldering, a crucial distinction when determining the status of a fire line. The DNB offers a unique capability to detect the areas of strong active flames by way of visible light emission.

In addition to its capability to detect the light emission from active fires, the DNB provides information that could be critical for determining fire behavior and evolution. In the western USA, the summer season of 2012 was marked by a rash of significant wildland fires, the culmination of years of drought coupled with hot, dry, and windy weather patterns. By the end of the calendar year, nearly 6.3 million acres of the west had been scorched by wildfires (http://www.nifc.gov/fireInfo/fireInfo stats_YTD2012.html). An outbreak of lightning-induced fires in Idaho accounted for over $25 \%$ of this devastation alone. Sudden wind shifts caused by thunderstorm outflows and even circulations produced by the fire itself contribute to danger in fighting these fires. At night, these local circulations can go undetected by thermal infrared satellite measurements due to their general lack of sensitivity to smoke plumes (the major mode for fresh smoke is $\sim 40 \mathrm{~nm}$, according to [84]) in the thermal infrared due to small size parameters (for the M15 band: $\chi=2 \pi \mathrm{r} / \lambda \sim 2 \pi \times(0.02 \mu \mathrm{m}) / 10.76 \mu \mathrm{m}=0.012<<1$ ). This represents a major shortfall using infrared data. However, with moonlight, and visible wavelength size parameters over an order of magnitude larger, the DNB provides dramatically improved detection of these plumes.

Figure 19 shows an example centered on the Mustang Complex Fire in Idaho, 2012. Daytime true color imagery (Figure 19a) shows the locations of numerous fires across the state. Figure 19b,c shows the thermal infrared (M15) and DNB imagery, respectively, of this same location as the fires continue to rage through the night. Whereas thermal infrared imagery detects some portions of the largest plumes (due presumably to the presence of relatively large particles close to the active fire lines that settle out rapidly), the DNB reveals significantly more detail. In addition, the DNB reveals the visible light emissions from the actively burning fire as bright patches of light seen at the heads of the plumes.

The extent to which this detection can be used to differentiate between areas of actively flaming fire and smoldering portions of the fire line is a research topic that remains to be explored. It is possible that the current characterization known as "hot spot" (currently based solely on infrared information) could be improved and refined as a result. Combining the DNB information with conventional hot spot 
detection from shortwave and thermal infrared bands may provide a way to further characterize fire lines in terms of actively burning and smoldering zones, using magnitude of light emission as a discriminator (smoldering areas will still produce some light from embers, but at a much reduced amount in comparison to an active fire). The VIIRS "Nightfire" algorithm [78] which, when combined with DNB measurements, may begin to answer such questions quantitatively. In terms of basic detection capability, the DNB is by far the most sensitive band for fire detection. In the VIIRS middlewave and longwave infrared bands, small fires that cover a small fraction of a pixel can go undetected because the radiance from the fire is averaged with the background irradiance, producing a negligible increase in brightness temperatures. In contrast, the scene radiance of surrounding non-flaming surfaces in DNB imagery is so much lower than fires (even with full moonlight) that even small/weak fires are readily detectable. In the aftermath of fires, lunar reflectance can reveal the extent of burn scarring via depressed surface albedo.

Figure 19. (a) Daytime VIIRS true color imagery showing a large outbreak of fires across Idaho on 28 August 2012, 2016 UTC. (b) Nighttime VIIRS M15 thermal infrared imagery (K) from the following evening (29 August 2012, 0832 UTC depicts significant hot-spots from a subset of the fires, but with little discernible smoke plume information. (c) Corresponding VIIRS DNB radiance imagery $\left(\log _{10}\left[\mathrm{~W} \cdot \mathrm{cm}^{-2} \cdot \mathrm{sr}^{-1}\right]\right)$ reveals the smoke plumes via lunar reflectance, as well as bright light emission from the flames (Inset photograph of Trinity Ridge fire courtesy of Kari Greer).

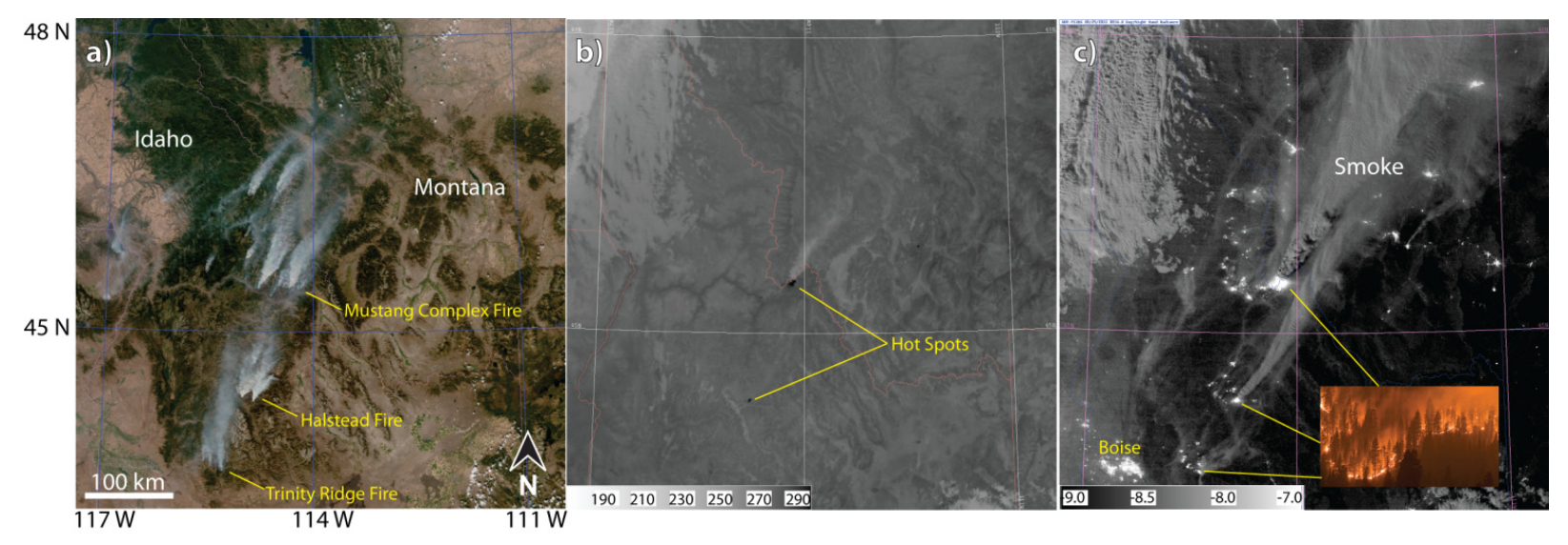

\subsection{Atmospheric Light Sources}

Considering the myriad ways in which moonlight and natural/artificial terrestrial light emissions offer useful information content, and in light of the fact that only the first item of Table 1 (NCC imagery) is currently included as part of the S-NPP/VIIRS EDR suite of operational products, it would be entirely reasonable to proclaim that 'the sky's the limit' for DNB. But even this is an understatement of sorts, as the sky itself provides sources of natural illumination. Not unlike the juxtaposition of the OLS and DNB sensors themselves, it is a story of something old (a feature seen in the earliest OLS imagery) and something new (features that even the designers of the DNB sensor had not anticipated) that brings us to a fitting close to this review of low-light visible capabilities. 


\subsubsection{Aurora}

Aurora light displays in the Arctic (borealis, or "northern lights") and Antarctic (australis, "southern lights") regions are caused by collisions between highly energized particles constituting the solar wind with atoms of the Earth's upper atmosphere. The inbound charged particles are channeled by Earth's magnetic field. The collisions between these particles and Earth's upper atmosphere produce light emissions that typically are confined to a region between $10^{\circ}$ and $20^{\circ}$ along the meridians from the magnetic poles, but on rare occasion can extend to mid-latitudes. By definition, "diffuse" (featureless) and "discrete" (sharply defined) aurorae are important indicators of geomagnetic activity from the Sun; the stronger a geomagnetic storm, the more intense the aurora and the further from the pole it can be seen. For example, strong ground-induced-currents in electric power grids can occur in association with aurora. The more intense the geomagnetic storm, the higher the potential for damage to power grids and sensitive electronics, including satellite equipment [85]. The Carrington Event of 1859 (e.g., [86]), the most intense solar storm on record, and which was accompanied by significant aurora activity at lower latitudes, is a dramatic example of the significant damage potential of solar storms to infrastructure. Increased aurora activity correlates with decreased performance (accuracy and availability) of the GPS/GNSS satellite navigation systems, which are heavily used by aviation, commerce, law enforcement, and the general public.

Figure 20 shows a DNB imagery example of aurora collected over Canada on 13 April 2012. The imagery was matched approximately to International Space Station (ISS) astronaut photography, providing a unique opportunity to view the features from two very different perspectives. The ISS is located over the northeastern Atlantic at the time of the photograph (Figure 20a). As indicated by blue arrows, the photograph view is toward the northwest. To facilitate reconciliation of the two very different perspectives (S-NPP view is closer to nadir, ISS more oblique), the distinct aurora bands are labeled as A1 and A2. Roughly 40 min later, the S-NPP satellite crossed on its nighttime descending node form the northeast toward the southwest, and the DNB imagery is shown in Figure 20b. Although auroras are known to change considerably over durations of only minutes, in this case similar features were present in both satellite passes. Moonlit clouds appear in the extreme eastern portion of the DNB image, but the Moon is below the eastern horizon for the remainder of the scene.

In Figure $20 \mathrm{~b}$ there is a notable difference in the appearance of the two auroras; the southern feature (A1) appears broader and more rippled/heterogeneous in contrast to the more laminar/sinuous appearance of the northern (A2) feature. The ISS photography, collected every second, can be looped to provide an animated view of the temporal behavior. Whereas the still photography of Figure 20a cannot show it, animation of such reveals a rapidly fluctuating and seemingly random distribution of bright patches superimposed upon the southern band, consistent with the speckled features present in the DNB instantaneous view. Occasionally the boundaries of these normally smoothly-varying, filamentary structures take on a more jagged appearance in DNB imagery. This is thought to be due to the sometimes rapid fluctuations of the "discrete" category aurora with respect to the $\sim 1.8$ s scan rate of the DNB (see [87]) — where the boundaries of the aurora have moved/changed considerably during the time between adjacent scans. Such artifacts help to distinguish aurora from meteorological clouds, since the motion between adjacent scans of the latter are negligible compared to the $750 \mathrm{~m}$ spatial resolution of the sensor. 
Figure 20. (a) International Space Station Nikon D3S photograph taken on 13 April 2012, 0558 UTC shows two distinct auroral bands (southern band A1, overlapping the northern band A2 in this limb view) on the horizon over Canada. (b) VIIRS DNB radiance imagery $\left(\log _{10}\left[\mathrm{~W} \cdot \mathrm{cm}^{-2} \cdot \mathrm{sr}^{-1}\right]\right)$ from the same evening at 0635 UTC captures the bands. Blue arrow and annotated city lights are provided for viewing orientation. (ISS photo courtesy of the Image Science and Analysis Laboratory, NASA Johnson Space Center).

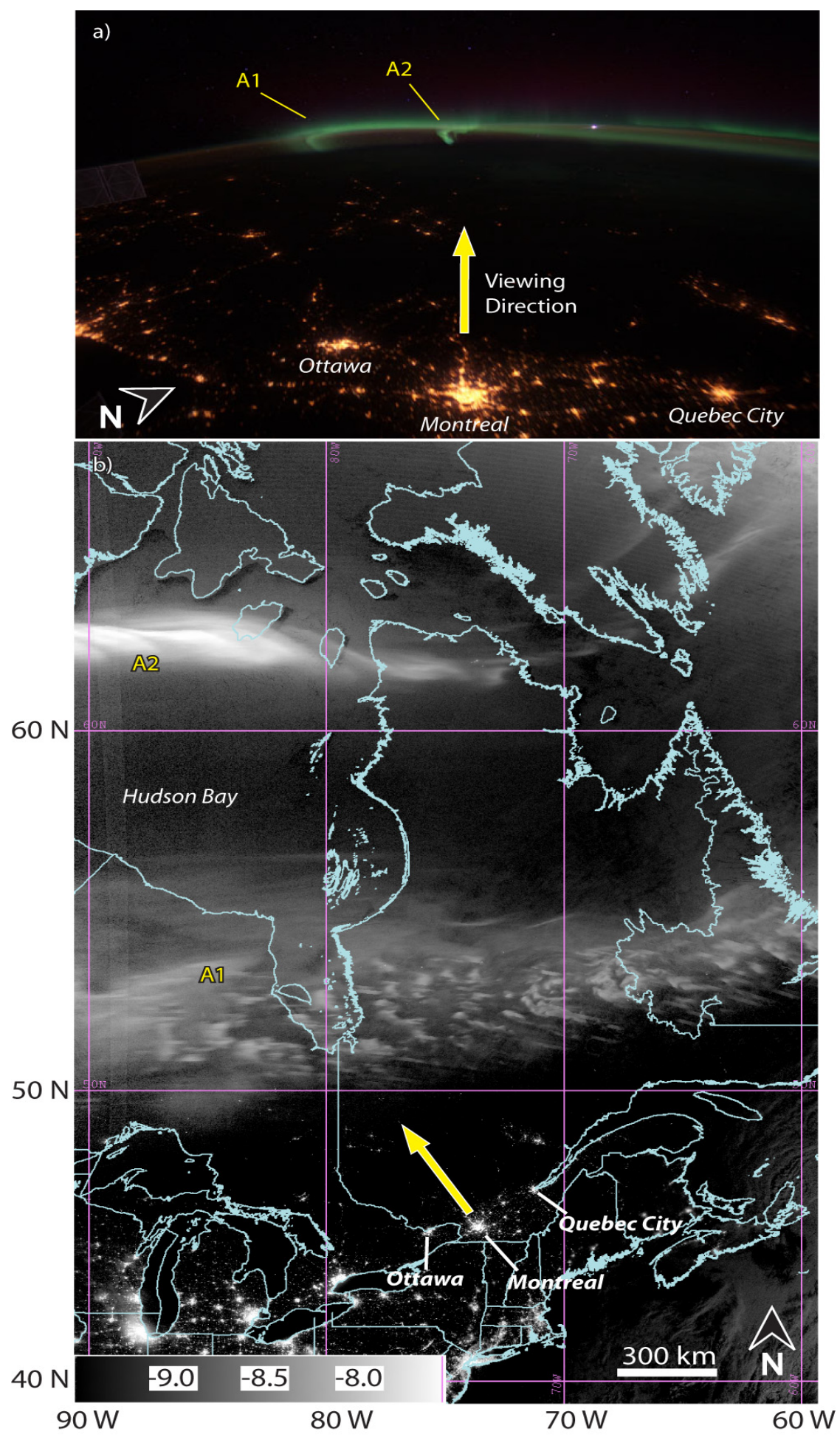




\subsubsection{Nightglow}

The recent discovery that the VIIRS/DNB has sufficient sensitivity to detect the emission and reflection of atmospheric nightglow in a way previously undocumented by the OLS transforms the conventional paradigms of visible light imaging. The unanticipated capability came to light during sensor check-out while the DNB calibration team searched for completely dark scenes required for sensor noise characterization [88]. While examining New Moon imagery over the open Pacific Ocean, they noted obvious meteorological clouds, even though there was no ostensive source of visible light that would account for their illumination. The principal source of illumination for these clouds is the atmosphere itself. Nightglow (e.g., [89]) describes an assortment of photochemical reactions occurring in the upper atmosphere (peaking near the mesopause, around 85-90 km). Here, excited hydroxyl $\left(\mathrm{OH}^{*}\right)$ molecules near $87 \mathrm{~km}$ produce a particularly strong signal within the band pass of the DNB. The reactions produce a faint but discernible emission that is readily apparent in ISS limb-viewing photographs. Although not designed for detection of nightglow signals, the DNB response function provides sufficient overlap with these emissions for their detection at the extreme limits of instrument sensitivity (where the band-integrated signals are $\sim 10^{-6} \mathrm{~W} \cdot \mathrm{m}^{-2} \cdot \mathrm{sr}^{-1}$ ). The implication is that a form of visible light-based meteorological imagery exists on all nights, with or without moonlight.

In addition to detecting the reflection of the integrated nightglow source (which is augmented near the horizon due to the van Rhijn effect), the DNB is also capable of detecting the direct emission of the nightglow layer itself, both in terms of broad synoptic-scale (order 1,000 km) structures of glowing atmosphere variability and also mesoscale (order 10-100 km) gravity waves patterns the mesopause region. Figure 21 shows these waves produced by a line of springtime thunderstorms in western Texas. The waves are generated by the deepest intense rain events in storms that can overshoot the tropopause, forcing excitation of gravity waves into the stratosphere which play an important role in the upper atmospheric circulation (e.g., [90]). A subset of the spectrum of waves generated that are of sufficiently large scale, large phase speed and small initial amplitude so as not to reach critical levels in the lower atmosphere will survive dissipation in the lower stratosphere-propagating through the middle atmosphere and up to the mesopause (e.g., [91]). Figure 21a shows VIIRS/M15 thermal infrared imagery of the cold thunderstorm anvil tops, and Figure $21 \mathrm{~b}$ shows the corresponding DNB imagery, with some of the nightglow wave forms (having wavelength $\lambda=30-35 \mathrm{~km}$ ) noted by arrows. Figure 21c shows the nightglow waves recorded by low-light camera observations in Lamy, New Mexico, looking toward the west and observing the northward propagating section of the wave train. The "epicenter" of the concentric wave train appears displaced to the west of the current position of the convection, consistent in this case with $\mathrm{a} \sim 1-2 \mathrm{~h}$ theoretical vertical propagation time under conditions of calm intervening winds [92] and the concurrent eastward propagation of the storms. Due to the extremely low intensities of nightglow emission, near the noise floor of the DNB, this imagery often appears granulated. The limitation, combined with the variable nature of this diffuse (non-direct-beam) light source, presents considerable research challenges for utilizing the nightglow measurements in a consistent and intuitive way. 
Figure 21. (a) VIIRS M15 thermal infrared imagery on 15 April 2012, 0746 UTC shows a line of nocturnal thunderstorms over Texas. (b) VIIRS DNB nightglow imagery reveals a concentric ring pattern corresponding to vertically-forced gravity waves reaching the mesopause and propagating radially. (c) Surface-based low-light camera photography from Lamy, NM earlier that same evening ( 0430 UTC; location and viewing direction noted in (b)) confirms waves from the same event. (Adapted from Figure S6 of [88]).

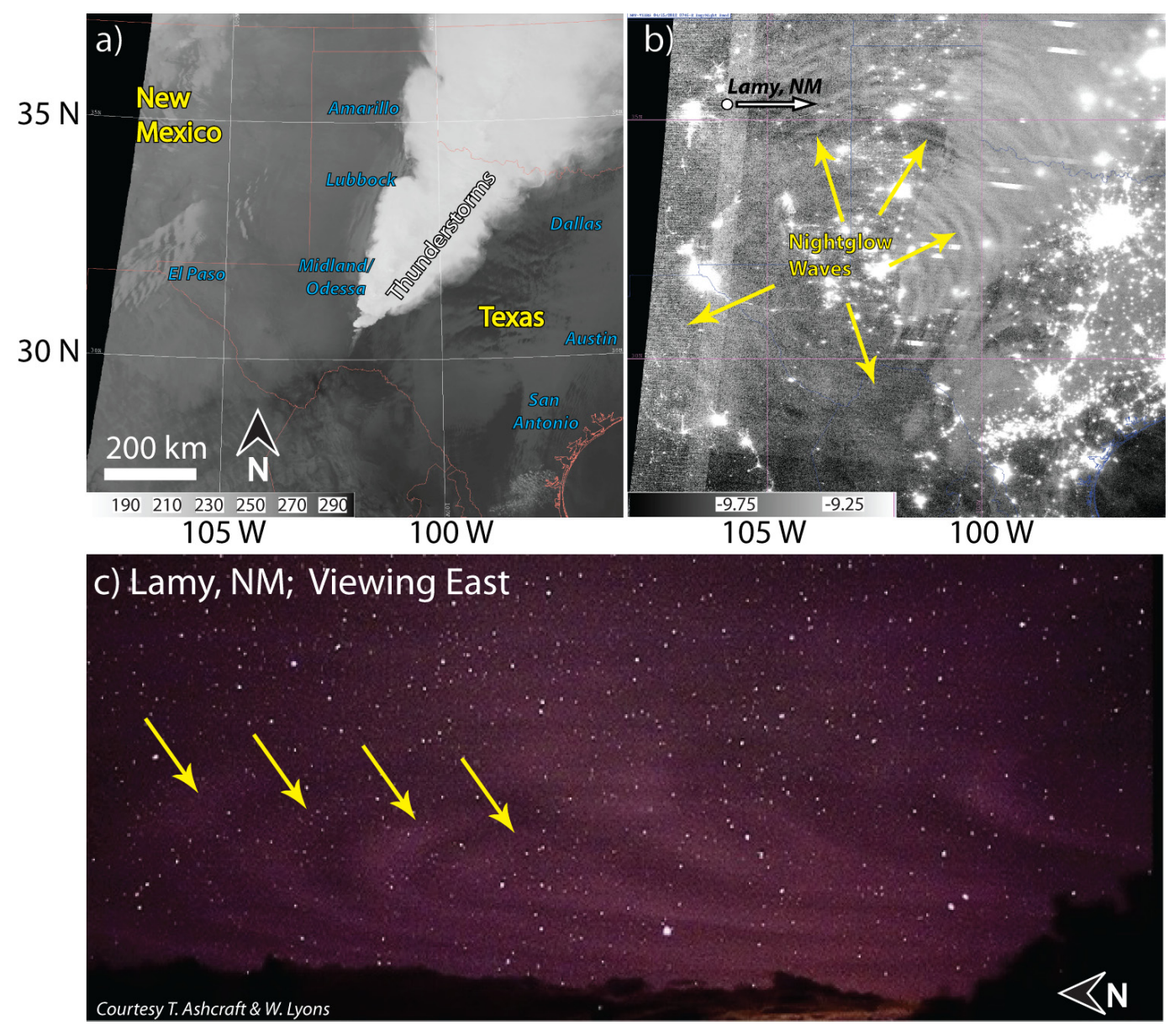

\section{The Research and Operational Potential}

\subsection{Climate Research}

Global, sustained, and well-calibrated observations are crucial for providing climate data records (CDRs) essential to assessing and understanding climate change [93]. Whereas viable satellite-based climate records dating back to the 1960s may give the sense that it is too late to introduce a new and unconventional observation such as low-light visible, the satellite era itself is still very much in its infancy. Fundamental improvements to the diurnal detection and characterization of key climate variables become possible only if such observations are sustained and improved upon over time. Here, quantitative nighttime low-light visible sensing measurements can help observe climate variables whose diurnal cycles are currently not well characterized or understood. One illustrative example is touched upon below-improved nocturnal cloud coverage and related improvements to sea surface 
temperature CDRs - but similar statements could be made for other parameters highlighted in Section 3 (snow, sea ice, aerosol, etc.).

An immediate topic of CDR benefit with regard to low-light visible imagery is the global climatology of cloud cover and cloud optical properties. Cloud albedo monitoring The International Satellite Cloud Climatology Project (ISCCP; e.g., [94,95]) produces a global climatology of cloud amount and basic properties (cloud top height and optical thickness) dating back to 1983. A simple mapping between cloud top pressure and optical thickness provides an estimate of cloud type as well [96]. Here, improved detection of nocturnal cloud cover (Figure 14) and the enabling of improved optical depth retrievals (Figure 13) during the portion of the lunar cycle when moonlight is available would strengthen these data records. In particular, the current spectral suite of satellite observations utilized by ISCCP has difficulty detecting optically thick clouds with low tops at night [97]. However, full capture of the diurnal cycle would require such measurements on geostationary satellites.

Improving nocturnal cloud cover should yield indirect benefits the global Sea Surface Temperature (SST) CDR. Satellite-based retrieval of SST, a measure of the skin (top $\sim 1 \mathrm{~mm}$ ) temperature, is a benchmark parameter for monitoring long-term climate change owing to the tight coupling between the ocean and atmosphere. Satellite-based retrievals using multispectral observations in the infrared have been conducted routinely since the early 1980s (e.g., [98,99]). To reduce biases related to skin temperature warming in regions of lower wind speed (and less mixing, leading to warming of up to $3{ }^{\circ} \mathrm{C}$ in these areas; e.g., $\left.[100,101]\right)$ the SST CDR is based on nighttime retrievals. Whereas the DNB is a shortwave sensor that does not provide direct information about SST (apart from limited information in the moon glint zone), its ability to improve the detection low clouds at night assists cloud filtering in SST retrievals (which require clear views of the ocean surface) by reducing cool biases introduced by missed clouds. It is also worth noting here that undetected sea ice (another CDR) can lead to significant SST errors at high latitudes (e.g., [102])—here, DNB information on sea ice extent via lunar reflectance (e.g., Figure 5) stands to play a useful role for both CDRs.

\subsection{Operational Stakeholders}

The numerous imagery examples presented above illustrate the many ways in which operational forecasters stand to benefit from the DNB's ability to improve characterization of the nocturnal environment. The National Weather Service (NWS) has begun to use DNB imagery routinely in its forecasts and public awareness statements. Independence from the limitations of poor thermal contrast, additional cloud-top and surface detail afforded by reflection from a direct-beam (lunar) light source, and high sensitivity over a broad dynamic range of radiance brings unprecedented advances to the operational platform. Whether used in a data-assimilation mode to improve NWP model analysis, as imagery for verification, or in combination with other measurements and forecaster experience to improve near-casting of local weather phenomena, DNB data shift the paradigm of capability in the forecaster's favor.

High latitude users enjoy particular benefits from DNB observations, as they face a wide array of significant forecasting challenges related to both surface and atmospheric hazards. Coast guard operations, fishery operations, commerce shipping support, and both commercial and private aviation operations rely heavily on accurate weather information on sea ice, fog, and volcanic ash. Due to 
Earth's $\sim 23.5^{\circ}$ axial tilt with respect to the ecliptic, day length at high latitudes during the winter season is dramatically reduced (to the extent of perpetual wintertime darkness poleward of the Arctic and Antarctic circles). The extent of darkness varies from civil twilight, when the Sun is $6^{\circ}$ or less below the horizon to astronomical darkness, when the Sun is at least $18^{\circ}$ below the horizon. In most cases, however, even levels of illumination under civil twilight are too low to provide useful signal to conventional visible-band sensors.

In this regard, the DNB's ability to amplify a continuum of light levels spanning the full day/night range provides particularly high value. Almost as an astronomical apology to the high latitudes for this dearth of light, there is a relative increase in moonlight brightness during the winter months. The lunar orbit is in fact more closely aligned with the ecliptic plane (with an inclination of $\sim 5^{\circ}$ ) than with the equatorial plane. This means that winter night moons, being opposite to the Sun, are inherently higher in the sky than they are on summer nights (for a given lunar phase) — offering larger lunar reflectance by virtue of larger values of $\mu_{m}$ (see Equation (1)). In addition, the S-NPP polar-orbit provides significantly enhanced swath overlap at high latitudes, useful for nighttime moonlight applications [103].

Human activities span the diurnal cycle, leading to the global proliferation of artificial light sources upon the invention of electrical lighting. Agencies such as the National Parks Service and advocacy groups such as the International Dark-Sky Association (IDA) conduct research and promote public awareness on the effects of light pollution. Information on light pollution is of prime importance to the astronomy community, prompting the compilation of world atlas of global anthropogenic lighting based on DSMP observations [104]. The ecological impacts of light pollution lead to regime-altering terrestrial and aquatic habitats, affecting various species in ways that we are only beginning to understand (e.g., [105]). Here, DNB information on city light emissions can be used to improve light source databases and terrestrial simulations of light pollution.

The DoD has utilized low-light visible information from the DMSP/OLS for many years to improve nighttime environmental awareness in support of tactical applications and operational safety. In general, the entire scope of environmental parameters described herein maintains high relevance to DoD operations. Historically, the OLS has supported the USA Air Force real-time automated nephanalyses (e.g., [106,107]) useful for model cloud/moisture field initialization, cloud parameterization, short-term trajectory-based cloud forecasting (e.g., [108]) and cloud verification. More recently, the USA Navy has invested in readiness for the VIIRS/DNB, including development of the DNB-specific lunar irradiance model described herein.

In the three-orbit constellation envisioned originally by the erstwhile National Polar-orbiting Operational Environmental Satellite System (NPOESS) concept, wherein three 4-hr space orbits (0530, 0930, and 1330 nodal crossing times) the early morning (0530) orbit was to succeed the DMSP constellation. The three orbits are in fact complementary in their ability to sample a greater portion of the lunar cycle [103]. Within the present Initial Joint Polar System (IJPS) concept, the European Organisation for the Exploitation of Meteorological Satellites (EUMETSAT) and NOAA have partnered to provide partial coverage of the mid-morning (0930; Meteorological Operational-MetOp) and early afternoon (1330; S-NPP/JPSS) orbits, respectively. The DoD is considering options for a possible follow-on weather satellite program at this time. Details of anticipated orbital plane and sensor capabilities remain pending, although an early-morning ( 0530) orbit would appear most likely in consideration of leveraging IJPS and providing continuity to the heritage DMSP. 


\section{The Merits of a Geostationary Capability}

At present, global low-light visible capabilities reside only on the DMSP and JPSS series (beginning with S-NPP). It has already been decided that the next-generation EUMETSAT Polar System (Post-EPS) will not feature a low-light visible sensor, and the potential DoD-operated system specifications have not yet been defined. As a result, it may well turn out that the JPSS series will offer the only low-light visible capability on the operational polar-orbiting constellation for the next 1-2 decades, at least by way of the currently planned systems. Whereas the JPSS sun-synchronous orbits provide a regular synoptic update of information for initializing numerical weather prediction models, the infrequency (one pass per night at the equator) of updated information at a particular location makes observations far less useful for monitoring the rapid evolution of weather and associated hazards. While polar orbits offer inherently more overlap at higher latitudes, the temporal resolution is limited by an orbital period which will produce temporal coverage gaps $>90 \mathrm{~min}$.

There exist alternative satellite orbits that offer a partial solution to these limitations. Satellites placed into the well-known geostationary (GEO) orbit match the rotation rate of Earth and appear to nearly hover over their sub-satellite locations. Only minor orbital corrections are necessary to offset the drift-inducing effects of Earth non-sphericity, solar/lunar gravity, and other forces such as the solar wind. The temporal resolution for sensors on GEO satellites is limited only by the hardware. Spatial coverage is limited to the field of satellite view, usually regarded as $60^{\circ}$ great circle distance on Earth's surface from the projected sub-satellite location for useful observations, but in theory can extend up to a maximum of about $80^{\circ}$. Highly elliptical orbits (HEO), such as the Molniya-type (e.g., [109]) and its dual-satellite optimization for yielding continuous observations over the poles (e.g., [110]) offer a superior solution for achieving a continuous imaging capability in the Polar Regions.

There are many potential benefits to improving the temporal resolution of the low light visible observations, many of which can be imagined from the snap-shot examples presented herein. Researchers and forecasters alike would benefit from diurnally-resolved cloud (ISCCP, mentioned above), dust, smoke, and volcanic ash detection and property information. Such observations would improve abilities to monitor the exact onset and evolution of fog over cold land surfaces, or visualize low cloud rotation to further improve tropical cyclone center fixing. Snow and ice detection, which may be obscured by opaque clouds at the time of a single overpass, would benefit from additional opportunities for detection as the cloud field evolves. The monitoring of electric and gas flare light emissions would allow for improved characterization of light pollution temporal changes, assist emergency managers in response to natural disasters (power outage/recovery), and changing lights over the evening hours to serve as better proxies for anthropogenic $\mathrm{CO}_{2}$ emission. Detecting the initiation of small fires (e.g., nocturnal dry lightning events) and the evolution fires lines would benefit wildfire management. The detailed trajectories of illuminated ships could also be tracked in real-time. The ability to resolve the scale and phase speed of vertically propagating gravity waves via nightglow signatures at the mesopause, approximated now only by way of crude parameterizations and few observational constraints, would provide a fundamental advance in our understanding of middle atmosphere circulations [111], including the quasi-biennial oscillation (QBO; [112]). These waves have also been detected from the surface in association with the Tohoku earthquake and tsunami [113], which occurred several months prior to the launch of S-NPP, raising the possibility of using a GEO 
low-light visible band in the context of tsunami early warning (complementing the moored buoy networks) over the sparsely observed ocean basins.

There are several hardware challenges unique to the GEO/HEO platforms which would need to be addressed via engineering studies, including: (i) accounting for solar intrusion (avoidance of stray light contamination in the focal plane array optics; a greater consideration at GEO/HEO orbits which seldom reside in Earth's umbral shadow apart from the "eclipse seasons"), (ii) trade-offs between spatial/spectral/temporal/radiometric resolution and dynamic range of sensitivity vis-à-vis sensor dwell time, platform stability, and data rates. In some instances, elements of legacy DNB technology could be leveraged, but in any case a new sensor design would be required. Details of these various considerations are beyond the scope of this paper, and will be addressed in future communications, but suffice to say here that none of them appear to be technology prohibited.

Figure 22. Comparisons of city lights over Kuwait City, Kuwait for (a) qualitative DMSP OLS F-18 satellite imagery from 4 November 2013, 1620 UTC, (b) quantitative S-NPP VIIRS DNB radiances $\left(\mathrm{W} \cdot \mathrm{cm}^{-2} \cdot \mathrm{sr}^{-1}\right)$ from 4 November 2013, 2214 UTC, and (c) reference International Space Station nighttime photography from 9 August 2012, 2343 UTC, illustrating the increasing information content afforded by higher spatial resolution as well as the ability of multispectral low-light visible imagery to distinguish between different electric light sources via coloration properties. (ISS-032-E-17635 photo courtesy of the Image Science and Analysis Laboratory, NASA Johnson Space Center)
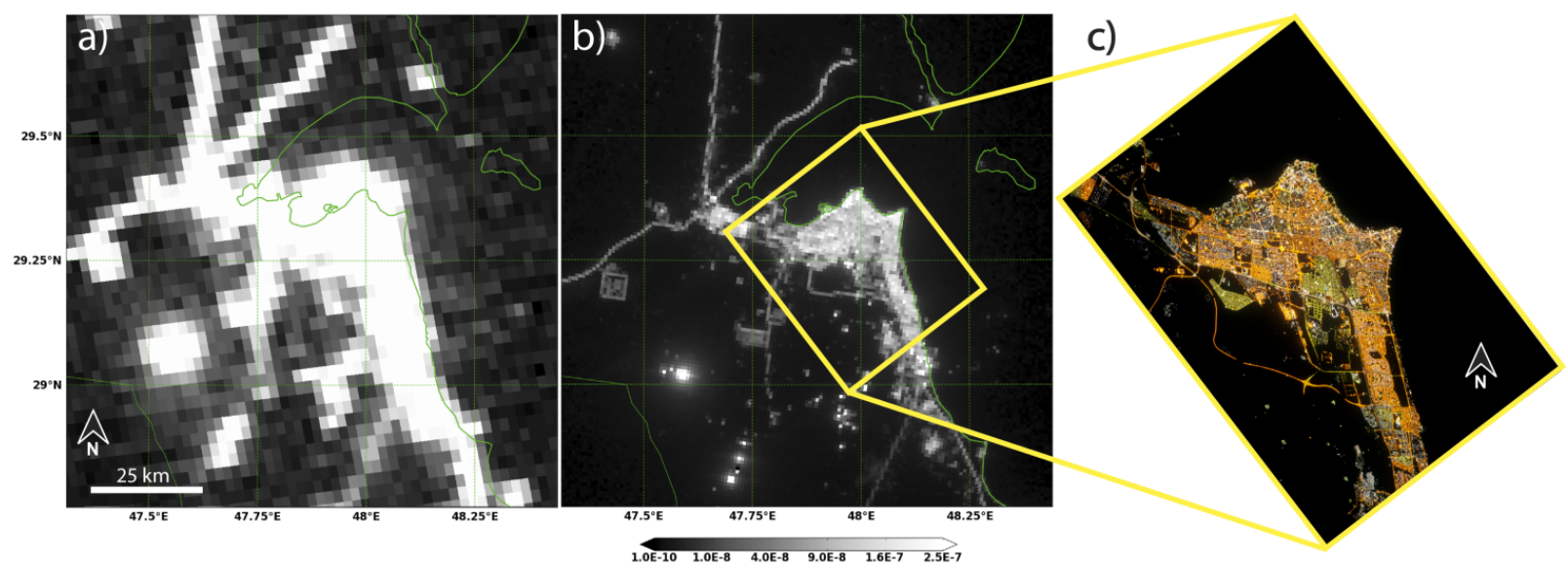

Lessons learned from the DNB would suggest that a multi-spectral capability, offering multiple bands in the visible spectrum, would expand low-light visible utility. For example, the Nightsat satellite concept [114] describes the benefits of multi-spectral visible measurements as a means to distinguishing the type and character of various electrical light sources (e.g., mercury vapor, high/low pressure sodium vapor, and halogen). Figure 22, which contrasts DMSP/OLS and VIIRS/DNB, imagery with International Space Station (ISS) low-light visible over Kuwait City, Kuwait, shows how spectrally-resolved visible light reveals differences in these sources (while also demonstrating the incremental improvements realized by higher spatial resolution as well as the general potential of ISS data to provide beneficial context to DNB). As evidenced by the ISS inset (Figure 22c), such coloration information would be most beneficial for urban typology (e.g., [115]) if provided at spatial 
resolutions coinciding with the scale of the features, and thus require $\sim 25-50 \mathrm{~m}$ resolution that is better suited for a low Earth orbiting (LEO) satellite [114]. With that said, color information from a full $\mathrm{red} / \mathrm{green} / \mathrm{blue}$ (3-band) system would nonetheless add a new dimension to current low-light visible observations, further improving fire characterization, delineating aurora from clouds, and enabling the first nighttime true color imagery from moonlight. A simpler, two-band system could be optimized to exploit "unconventional" low-light visible signals mentioned in this paper, such as a red/near-infrared for exploiting nightglow signals, or tuned to shorter wavelengths to avoid nightglow and improve chances for detection of bioluminescent Milky Seas while remaining applicable to all the other concepts noted in Section 3. Coupling these low-light visible measurements with other bands in the thermal infrared, either by way of inclusion on same sensor suite or coordinating observations with another satellite providing this information, would enable superior capabilities to VIIRS.

\section{Conclusions}

In this paper we have highlighted several of the capabilities of the Suomi National Polar-orbiting Partnership (S-NPP) satellite's Visible Infrared Imaging Radiometer Suite (VIIRS) Day/Night Band (DNB) sensor in terms of new/improved environmental parameter detection and characterization at night. The DNB represents a significant technological advance over its predecessor, the Defense Meteorological Satellite Program (DMSP) Operational Linescan System (OLS) in terms of spatial (45-88 times higher) and radiometric resolution (256 times finer), sensitivity ( $\sim 10$ times higher), and calibration (transferred from on-board solar diffuser information, $v s$. un-calibrated).

The improved measurements, when coupled with other VIIRS emissive bands, enable the leveraging of moonlight to assist in a number of nocturnal applications, including the detection of snow cover, rainfall distributions across arid/semi-arid surfaces, the ability to peer through optically thin clouds to reveal sea ice, the detection of oceanic currents, slicks, turbidity and internal waves, the improved detection of low clouds, dust, smoke and ash, and the first representative nighttime cloud optical depth retrievals. However, moonlight is available only for $\sim 1 / 2$ of the 29.5 day lunar cycle, thus limiting routine applications. In the absence of moonlight, however, the DNB retains important capabilities in the context of detecting and characterizing anthropogenic light sources (e.g., cities and power outages, the movement of ships, natural gas flares, slash-and-burn activities, etc.) and the natural emissions of forest fires, lightning flashes, and aurora. The recent discovery of the DNB's sensitivity to atmospheric nightglow, and the previously demonstrated ability of the OLS to detect bioluminescent milky seas, represents new pathways for future interdisciplinary research.

Our survey of DNB capabilities is by no means a comprehensive one; in practice, the uses of these nighttime visible data are indeed as diverse as those requiring daytime visible measurements. We have bracketed our selected examples within the framework of the Earth systems "spheres"- the cryosphere, hydrosphere, lithosphere, atmosphere, and biosphere — as a way of highlighting the myriad possibilities of this new sensor throughout and across these disciplines, with benefits spanning from night-to-night operations to improved climate data records for clouds (i.e., quantitative retrievals of cloud optical depths exceeding values of $\sim 10$ are now possible on moonlit nights) and parameters reliant on accurate nocturnal cloud masks, such as sea surface temperature. Many of the examples demonstrated in this review have not yet been explored in depth, and represent fertile ground for new 
and heretofore unpublished research, and we anticipate that the scientific literature will expand in accommodation of research based on the new quantitative low-light visible information.

Whereas the DNB represents the state-of-the-art in nighttime low-light visible measurements, important knowledge gaps in the diurnal properties of many of the parameters mentioned here will remain, due to the polar-orbiting nature of S-NPP. Looking ahead, and given the early success and widespread research and operational interest surrounding the novel DNB measurements, it is possible that similar technology will one day find its way to geostationary or highly-elliptical orbits in future satellite generations in order to realize the benefits of high temporal data refresh rates. The measurements would further assist in characterizing the ephemeral nature of both the weather and the myriad light emissions (evolving fire lines, diurnal trends in cloud properties, the movement of fishing fleets, nightglow wave phase speed determination, etc.). There will be an opportunity to refine the character of the measurements at that time. Lessons learned from our current experiences with the DNB will help to guide those sensor specification decisions.

\section{Acknowledgments}

We thank our Reviewers and Remote Sensing's Chief Editor for their helpful recommendations toward improving this manuscript. We also thank Jody Russell [Image Science and Analysis Laboratory, National Aeronautics and Space Administration Johnson Space Center (NASA-JSC)] and William Stefanov [International Space Station Program Science Office, NASA-JSC] for their assistance with acquiring ISS photography, Scott Bachmeier (Cooperative Institute for Meteorological Satellite Studies (CIMSS), U. Wisconsin-Madison; http:/cimss.ssec.wisc.edu/goes/blog/) for suggested case studies, and Dan Lindsey (NOAA/NESDIS) and Russ Schumacher (Colorado State University) for their assistance with radar datasets. Support of the NOAA Joint Polar Satellite System Cal/Val and Algorithm Program, the Naval Research Laboratory (BAA Contract \#N00173-10-C2003), and the Oceanographer of the Navy through the program office at the PEO C4I/PMW-120 under program element PE-0603207N is gratefully acknowledged.

\section{Conflicts of Interest}

The authors declare no conflict of interest.

\section{References}

1. Lewis, J.M.; Martin, D.W.; Rabin, R.M.; Moosmüller, H. Suomi: Pragmatic visionary. Bull. Am. Meteorol. Soc. 2010, 91, 559-577.

2. Lee, T.F.; Miller, S.D.; Turk, F.J.; Schueler, C.; Julian, R.; Deyo, S.; Dills, P.; Wang, S. The NPOESS/VIIRS day/night visible sensor. Bull. Am. Meteorol. Soc. 2006, 8, 191-199.

3. Wark, D.Q.; Popham, R.W. TIROS I observations of sea ice in the Gulf of St. Lawrence. Mon. Wea. Rev. 1960, 88, 182.

4. Elvidge, C.D.; Baugh, K.E.; Kihn, E.A.; Kroehl, H.W.; Davis, E.R. Mapping of city lights using DMSP operational linescan system data. Photogramm. Eng. Remote Sens. 1997, 63, 727-734. 
5. Elvidge, C.D.; Safran, J.; Nelson, I.L.; Tuttle, B.T.; Hobson, V.R.; Baugh, K.E.; Dietz, J.B.; Erwin, E.H. Area and Position Accuracy of DMSP Nighttime Lights Data. In Remote Sensing and GIS Accuracy Assessment; Lunetta, R.S., Lyon, J.G., Eds.; CRC Press: Florida, FL, USA, 2004; pp. 281-292.

6. Elvidge, C.D.; Baugh, K.E.; Zhizhin, M.; Hsu, F.-C. Why VIIRS data are superior to DMSP for mapping nighttime lights. Proc. Asia-Pacific Adv. Netw. 2013, 35, 62-69.

7. Schueler, C.; Lee, T.F.; Miller, S.D. VIIRS constant spatial-resolution advantages. Int. J. Remote Sens. 2013, 34, 5761-5777.

8. Liao, L.B.; Weiss, S.; Mills, S.; Hauss, B. Suomi NPP VIIRS Day and Night Band (DNB) on-orbit performance. J. Geophys. Res. 2013, doi:10.1002/2013JD020475.

9. Mills, S.; Jacobson, E.; Jaron, J.; McCarthy, J.; Ohnuki, T.; Plonski, M.; Searcy, D.; Weiss, S. Calibration of the VIIRS Day/Night Band (DNB). In Proceedings of American Meteorological Society 6th Annual Symposium on Future National Operational Environmental Satellite Systems-NPOESS and GOES-R, Boston, MA, USA, 4 September 2010.

10. Jacobson, E; Ibara A.; Lucas M.; Menzel R.; Murphey H.; Yin F; Yokoyama K. Operation and Characterization of the Day/Night Band (DNB) for the NPP Visible/Infrared Imager Radiometer Suite (VIIRS). In Proceedings of American Meteorological Society 6th Annual Symposium on Future National Operational Environmental Satellite Systems-NPOESS and GOES-R, Boston, MA, USA, 2010; p.349.

11. Kieffer H.H.; Stone, T.C. The spectral irradiance of the Moon. Astron. J. 2005, 129, 2887-2901.

12. Miller, S.D.; Turner, R.E. A dynamic lunar spectral irradiance dataset for NPOESS/VIIRS Day/Night Band nighttime environmental applications. IEEE Trans. Geosci. Remote Sens. 2009, 47, 2316-2329.

13. Mueller, R.; Trentmann, J.; Träger-Chatterjee, C.; Posselt, R.; Stöckli, R. The role of the effective cloud albedo for climate monitoring and analysis. Remote Sens. 2011, 3, 2305-2320.

14. Baker, N. JPSS VIIRS Imagery Products Algorithm Theoretical Basis Document (ATBD); Goddard Space Flight Center: Greenbelt, MD, USA, 2011.

15. Key, J.; Drinkwater, M.; Ukita, J. Integrated Global Observing Strategy Cryosphere; Theme Report WMO/TD-No. 1405; World Meteorological Organization: Geneva, Switzerland, 2007; p. 100.

16. Allen, R.C.; Durkee, P.A.; Walsh, C.H. Snow/cloud discrimination with multispectral satellite measurements. J. Appl. Meteorol. 1990, 29, 994-1004.

17. Miller, S.D.; Lee T.F.; Fennimore, R. Satellite-based daytime imagery techniques for snow cover and cloud delineation. J. Appl. Meteorol. 2005, 44, 987-997.

18. Zhang, Y.; Yan, S.; Lu, Y. Snow cover monitoring using MODIS data in Liaoning Province, Northeastern China. Remote Sens. 2010, 2, 777-793.

19. Chokmani, K.; Bernier, M.; Royer, A. A merging algorithm for regional snow mapping over eastern Canada from AVHRR and SSM/I data. Remote Sens. 2013, 5, 5463-5487.

20. Notarnicola, C.; Duguay; M.; Moelg, N.; Schellenberger, T.; Tetzlaff, A.; Monsorno, R.; Costa, A.; Steurer, C.; Zebisch, M. Snow cover maps from MODIS images at $250 \mathrm{~m}$ resolution, Part 1: Algorithm description. Remote Sens. 2013, 5, 110-126. 
21. Notarnicola, C.; Duguay; M.; Moelg, N.; Schellenberger, T.; Tetzlaff, A.; Monsorno, R.; Costa, A.; Steurer, C.; Zebisch, M. Snow cover maps from MODIS images at $250 \mathrm{~m}$ resolution, Part 2: Validation. Remote Sens. 2013, 5, 1568-1587.

22. Tardif, R.; Rasmussen, R.F. Process-oriented analysis of environmental conditions associated with precipitation fog events in the New York City region. J. Appl. Meteorol. 2008, 47, 1681-1703.

23. Foster, J.L.; Hall, D.K. Observations of snow and ice features during the polar winter using moonlight as a source of illumination. Remote Sens. Environ. 1991, 37, 77-88.

24. Miller, S.D.; Lee, T.F.; Turk, F.J.; Kuciauskas, A.P.; Hawkins, J.D. Shedding new light on nocturnal monitoring of the environment with the VIIRS day/night band. Proc. SPIE 2005, 5890, doi:10.1117/12.619534.

25. Miller, S.D.; Schmidt C.; Schmit, T.; Hillger, D. A case for natural colour imagery from geostationary satellites, and an approximation for the GOES-R ABI. Int. J. Remote Sens. 2012, 33, 3999-4028.

26. Gleason, S. Towards sea ice remote sensing with space detected GPS signals: Demonstration of technical feasibility and initial consistency check using low resolution sea ice information. Remote Sens. 2010, 2, 2017-2039.

27. Chen, C.; Lakhankar, T.; Romanov, P.; Helfrich, S.; Powell, A.; Khanbilvardi, R. Validation of NOAA-interactive multisensor snow and ice mapping system (IMS) by comparison with ground-based measurements over continental United States. Remote Sens. 2012, 4, 1134-1145.

28. Maykut, G.A. Energy exchange over young sea ice in the central Arctic. J. Geophys. Res. 1978, $83,3646-3658$.

29. Hu, Y.X.; Stamnes, K. An accurate parameterization of the radiative properties of water clouds suitable for use in climate models. J. Clim. 1993, 6, 728-742.

30. Fett, R.W.; Mitchell, W.F. Techniques and Applications of Image Analysis; Naval Research Laboratory Applications Rep. 77-03; Naval Research Laboratory: Monterey, CA, USA, 1977; pp. 1-110.

31. Cox, C.; Munk, W. Measurement of the roughness of the sea surface from photographs of the Sun's glitter. J. Opt. Soc. Amer. 1954, 44, 838-850.

32. Zhang, Z.; Liu, L.; Liu, C.; Cai, W. Studies on the sea surface microlayer: II. The layer of sudden change of physical and chemical properties. J. Colloid Interface Sci. 2003, 264, 148-159.

33. Stanton, T.P.; Ostrovsky, L.A. Observations of highly nonlinear internal solitons over the continental shelf. Geophys. Res. Lett. 1998, 25, 2695-2698.

34. Fett, R.; Rabe, K. Satellite observation of internal wave refraction in the South China Sea. Geophys. Res. Lett. 1977, 4, 189-191.

35. Li, X.; Jackson, C.R.; Pichel, W. Internal solitary wave refraction at Dongsha Atoll, South China Sea. Geophys. Res. Lett. 2013, 40, 1-5.

36. McClain, C.R.; Feldman, G.C.; Hooker, S.B. An overview of the SeaWiFS project and strategies for producing a climate research quality global ocean bio-optical time series. Deep-Sea Res. Part. II. 2004, 51, 5-42.

37. Bailey, S.W.; Werdell P.J. A multi-sensor approach for the on-orbit validation of ocean color satellite data products. Remote Sens. Environ. 2006, 102, 12-23. 
38. Wang, M.; Shi, W. Estimation of ocean contribution at the MODIS near-infrared wavelengths along the east coast of the U.S.: Two case studies. Geophys. Res. Lett. 2005, 32, L13606.

39. Wang, M.; Tang, J.; Shi, W. MODIS-derived ocean color products along the China east coastal region. Geophys. Res. Lett. 2007, 34, L06611.

40. Sokoletsky, L.G.; Lunetta, R.S.; Wetz, M.S.; Paerl, H.W. MERIS retrieval of water quality components in the turbid albemarle-pamlico sound estuary, USA. Remote Sens. 2011, 3, 684-707.

41. Milliman, J.D.; Farnsworth, K.L. Runoff, erosion and delivery to the coastal ocean. River Discharge to the Coastal Ocean; Cambridge University Press: Cambridge, UK, 2011; p. 384.

42. Jackson, T.J. Measuring surface soil moisture using passive microwave remote sensing. Hydrol. Process. 1993, 7, 139-152.

43. Idso, S.B.; Jackson, R.D.; Reginato, R.J.; Kimball, B.A.; Nakayama, F.S. The dependence of bare soil Albedo on soil water content. J. Appl. Meteorol. 1975, 14, 109-113.

44. Chen, S.; Gourley, J.J.; Hong, Y.; Kirstetter, P.E.; Zhang, J.; Howard, K., Flamig, Z.L.; Hu, J.; Qi, Y. Evaluation and uncertainty estimation of NOAA/NSSL next-generation national mosaic QPE (Q2) over the continental United States. J. Hydrometeorol. 2013, 14, 1308-1322.

45. Siebert, L.; Simkin, T.; Kimberly, P. Volcanoes of the World, 3rd ed.; Smithsonian Institution, University of California Press: Washington, DC, USA, 2011; p. 568.

46. Miller, T.P.; Casadevall, T.J. Volcanic Ash Hazards to Aviation. In Encyclopedia of Volcanoes; Sigurdsson, H., Diego, S., Eds.; Academic Press Inc: San Diego, CA, USA, 2000; pp. 915-930.

47. Casadevall, T. The 1989-1990 eruption of Redoubt Volcano, Alaska-Impacts on aircraft operations. J. Volcanol. Geotherm. Res. 1994, 62, 301-316.

48. Pavolonis, M.J.; Heidinger, A.K.; Sieglaff, J. Automated retrievals of volcanic ash and dust cloud properties from upwelling infrared measurements. J. Geophys. Res. 2013, 118, 1436-1458.

49. Carter, A.; Ramsey, M. Long-term volcanic activity at Shiveluch Volcano: Nine years of ASTER spaceborne thermal infrared observations. Remote Sens. 2010, 2, 2571-2583.

50. Edwards, B.; Belousov, A.; Belousova, M.; Volynets, A.; Melnikov, D.; Chirkov, S.; Senyukov, S.; Gordeev, E.; Muraviev, Y.; Izbekov, P.; et al. Another "Great Tolbachik" eruption? Eos Trans. $A G U$ 2013, 94, 189-191.

51. Prospero, J.M. Long-term measurements of the transport of African mineral dust to the southeastern United States: Implications for regional air quality. J. Geophys. Res. 1999, 104, $15917-15927$.

52. Zhao, T.X.-P.; Ackerman, S.; Guo, W. Dust and smoke detection for multi-channel imagers. Remote Sens. 2010, 2, 2347-2368.

53. Zhang, J.; Reid, J.S.; Miller, S.D.; Turk, F.J. Strategy for studying nocturnal aerosol optical depth using artificial lights. Int. J. Remote Sens. 2008, 29, 4599-4613.

54. Johnson, R.S.; Zhang, J.; Hyer, E.J.; Miller, S.D.; Reid, J.S. Preliminary investigations toward 3 night time aerosol optical depth retrievals from the VIIRS Day/Night band. Atmos. Meas. Tech. 2013, 6, 1245-1255.

55. Trigo-Rodríguez, J.M.; Martín-Torres, F.J. Implication of Impacts in the Young Earth Sun Paradox and the Evolution of Earth's Atmosphere. In The Early Evolution of the Atmospheres of Terrestrial Planets, Astrophysics and Space Science Proceedings; Springer: New York, NY, USA, 2013; pp. 85-97. 
56. Stevens, B.; Lenschow, D.H.; Faloona, I.; Blomquist, B.; Vali, G.; Bandy, A.; Campos, T.; Gerber, H.; Haimov, S.; Morley, B.; et al. On entrainment rates in nocturnal marine stratocumulus. Q. J. R. Meteorol. Soc. 2003, 129, 3469-3493.

57. Jacob, C. Cloud cover in the ECMWF reanalysis. J. Clim. 1999, 12, 947-959.

58. Klein, S.A.; Hartmann, D.L. The seasonal cycle of stratiform clouds. J. Clim. 1993, 6, 1587-1606.

59. Chlond, A.; Müller, F.; Sednev, I. Numerical simulation of the diurnal cycle of marine stratocumulus during FIRE-An LES and SCM modelling study. Q. J. R. Meteorol. Soc. 2004, 130, 3298-3321.

60. Walther, A.; Heidinger, A.K. Implementation of the daytime cloud optical and microphysical properties algorithm (DCOMP) in PATMOS-x. J. Appl. Meteorol. Climatol. 2012, 51, 1371-1390.

61. Walther, A.; Heidinger, A.K.; Miller, S.D. The expected performance of cloud optical and microphysical properties derived from S-NPP VIIRS DNB lunar reflectances. J. Geophys. Res. 2013, In Press.

62. Minnis, P.; Szedun, S.-M.; Young, D.F.; Heck, P.W.; Garber, D.P.; Chen, Y.; Spangenberg, D.A.; Arduini, R.F.; Trepte, Q.Z.; Smith, W.L.; et al. CERES Edition-2 cloud property retrievals using TRMM VIRS and Terra and Aqua MODIS data, Part I: Algorithms. IEEE Trans. Geosci. Remote Sens. 2011, 49, 4374-4400.

63. Albrecht, B.A.; Randall, D.A.; Nicholls, S. Observations of marine stratocumulus clouds during FIRE. Bull. Am. Meteorol. Soc. 1988, 69, 618-626.

64. Boccippio, D.J.; Cummins, K.L.; Christian, H.J.; Goodman, S.J. Combined satellite- and surface-based estimation of the intracloud-cloud-to-ground lightning ratio over the continental United States. Mon. Wea. Rev. 2001, 129, 108-122.

65. Kasemir, H.W. Lightning Hazard to Rockets during Launch II. ESSA Technical. Report; Atmospheric Physics and Chemistry Laboratory: Athens, Greece, 1969.

66. Darden, C.B.; Nadler, D.J.; Carcione, B.C.; Blakeslee, R.J.; Stano, G.T.; Buechler, D.E. Utilizing total lightning information to diagnose convective trends. Bull. Am. Meteorol. Soc. 2010, 91, 167-175.

67. Pessi, A.T.; Businger, S. The impact of lightning data assimilation on a winter storm simulation over the North Pacific Ocean. Mon. Wea. Rev. 2009, 137, 3177-3195.

68. Fierro, A.O.; Mansell, E.R.; Ziegler, C.L.; MacGorman, D.R. Application of a lightning data assimilation technique in the WRF-ARW model at cloud-resolving scales for the tornado outbreak of 24 May 2011. Mon. Wea. Rev. 2012, 140, 2609-2627.

69. Norinder, H. Duration of lightning strokes and occurrence of multiple strokes. Tellus 1950, 2, $24-34$.

70. Bankert, R.L.; Solbrig, J.E.; Lee, T.F.; Miller, S.D. Automated lightning flash detection in nighttime visible satellite data. Wea. Forecast. 2011, 26, 399-408.

71. Kummerow, C.K.; Barnes, W.; Kozu, T.; Shiue, J.; Simpson, J. The Tropical Rainfall Measuring Mission (TRMM) sensor package. J. Atmos. Ocean. Tech. 1998, 15, 809-817.

72. Ruff, C.S.; Gleason, S.; Jelenak, Z.; Katzberg, S.; Ridley, A.; Rose, R.; Scherre, J.; Zavorotny, V. The CYGNSS Nanosatellite Constellation Hurricane Mission. In Proceedings of 2012 IEEE International Geoscience and Remote Sensing Symposium (IGARSS), Munich, FL, USA, 22-27 July 2012; pp. 214-216. 
73. Molthan, A.; Jedlovec, G. Satellite observations monitor outages from Superstorm Sandy. Eos Trans. AGU 2013, 94, 53-54.

74. Hawkins, J.D.; Lee, T.F.; Turk, J.; Sampson, C.; Kent, J.; Richardson, K. Real-time internet distribution of satellite products for tropical cyclone reconnaissance. Bull. Am. Meteorol. Soc. 2001, 82, 567-578.

75. Pan, Y.; Liu, A.K.; He, S.; Yang, J.; He, M.-X. Comparison of typhoon locations over ocean surface observed by various satellite sensors. Remote Sens. 2013, 5, 3172-3189.

76. Bielski, C; Gentilini, S.; Pappalardo, M. Post-disaster image processing for damage analysis using GENESI-DR, WPS and grid computing. Remote Sens. 2011, 3, 1234-1250.

77. Croft, T.A. Burning waste gas in oil fields. Nature 1973, 245, 375-376.

78. Elvidge, C.D.; Zhizhin, M.; Hsu, F.-C.; Baugh, K.E. VIIRS Nightfire: Satellite pyrometry at night. Remote Sens. 2013, 5, 4423-4449.

79. Oda, T.; Maksyutov, S.; Elvidge, C.D. Disaggregation of national fossil fuel $\mathrm{CO}_{2}$ emissions using a global power plant database and DMSP nightlight data. Proc. Asia-Pacific Adv. Netw. 2010, 30, 220-229.

80. Waluda, C.M.; Yamashiro, C.; Elvidge, C.D.; Hobson, V.R.; Rodhouse, P.G. Quantifying light-fishing for Dosidicus. gigas in the eastern Pacific using satellite remote sensing. Remote Sens. Environ. 2004, 91, 129-133.

81. Coakley, J.A.; Bernstein, R.L.; Durkee, P.A. Effect of ship stack effluents on cloud reflectivity. Science 1987, 237, 1020-1022.

82. Herring, P.J.; Watson, M. Milky seas: A bioluminescent puzzle. Mar. Obs. 1993, 63, 22-30.

83. Miller, S.D.; Haddock, S.H.D.; Elvidge, C.; Lee, T.F. Detection of a bioluminescent milky sea from space. Proc. Natl. Acad. Sci. USA 2005, 102, 14181-14184.

84. Hosseini, S.; Li, Q.; Cocker, D.; Weise, D.; Miller, A; Shrivastava, M.; Miller, J.W.; Mahalingam, S.; Princevac, M.; Jung, H. Particle size distributions from laboratory-scale biomass fires using fast response instruments. Atmos. Chem. Phys. 2010, 10, 8065-8076.

85. Odenwald, S.F.; Green, J.L. Bracing for a solar superstorm. Sci. Am. 2008, 299, 80-87.

86. Cliver, E.W. The 1859 space weather event: Then and now. Adv. Space Res. 2006, 38, 119-129.

87. Seaman, C.; Miller, S.D. Aurora motion VIIRS Day/Night Band. Bull. Am. Meteorol. Soc. 2013, 87, 191-199.

88. Miller, S.D.; Mills, S.P.; Elvidge, C.D.; Lindsey, D.T.; Lee, T.F.; Hawkins, J.D. Suomi satellite brings to light a unique frontier of environmental imaging capabilities. Proc. Natl. Acad. Sci. USA 2012, 109, 15706-15711.

89. Ingham, M.F. The light of the night sky and the interplanetary medium. Rep. Prog. Phys. 1971, 34, 875-912.

90. Alexander, M.J.; Holton, J.R.; Durran, D.R. The gravity response above deep convection in squall line simulation. J. Atmos. Sci. 1995, 52, 2212-2226.

91. Yue, J.; Vadas, S.L.; She, C.-Y.; Nakamura, T.; Reising, S.C.; Liu, H.-L.; Stamus, P.; Krueger, D.A.; Lyons, W.; Li, T. Concentric gravity waves in the mesosphere generated by deep convective plumes in the lower atmosphere near Fort Collins, Colorado. J. Geophys. Res. 2009, 114, D06104. 
92. Vadas, S.L.; Yue, J.; She, C.-Y.; Stamus, P.; Liu, A.Z. A model study of the effects of winds on concentric rings of gravity waves from a convective plume near Fort Collins on 11 May 2004. J. Geophys. Res. 2009, 114, D06103.

93. National Research Council. Climate Data Records from Environmental Satellites: Interim Report; The National Academies Press: Washington, DC, USA, 2004.

94. Schiffer, R.A.; Rossow, W.B. The International Satellite Cloud Climatology Project (ISCCP): The first project of the world climate research program. Bull. Am. Meteorol. Soc. 1983, 64, 779-784.

95. Rossow, W.B.; Schiffer, R.A. Advances in understanding clouds from ISCCP. Bull. Am. Meteorol. Soc. 1999, 80, 2261-2287.

96. Rossow, W.B.; Schiffer, R.A. ISCCP cloud data products. Bull. Am. Meteorol. Soc. 1991, 72, 2-20.

97. Han, C.J.; Rossow, W.B.; Warren, S.G. ISCCP cloud properties associated with standard cloud types identified in individual surface observations. J. Clim. 2001, 14, 11-28.

98. Deschamps, P.Y.; Phulpin, T. Atmospheric correction of infrared measurements of sea surface temperature using channels at 3.7, 11 and $12 \mu \mathrm{m}$. Bound.-Layer Meteor. 1980, 18, 131-143.

99. McClain, E.P.; Pichel, W.G.; Walton, C.C. Comparative performance of AVHRR-based multichannel sea-surface temperatures. J. Geophys. Res. 1985, 90, 1587-1601.

100. Price, J.F.; Weller, R.A.; Pinkel, R. Diurnal cycling: observations and models of the upper ocean response to diurnal heating, cooling, and wind mixing. J. Geophys. Res. 1986, 91, 8411-8427.

101. Yokoyama, R.; Tanba, S.; Souma, T. Sea surface effects on the sea surface temperature by remote sensing. Int. J. Remote Sens. 1995, 16, 227-238.

102. Hurrell, J.W.; Trenberth, K.E. Global sea surface temperature analyses: multiple problems and their implications for climate analysis, modeling, and reanalysis. Bull. Am. Meteorol. Soc. 1999, 80, 2661-2678.

103. Miller, S.D.; Combs, C.; Kidder, S.Q.; Lee, T.F. Assessing global and seasonal lunar availability for nighttime low-light visible remote sensing applications. J. Atmos. Ocean. Tech. 2012, 29, 538-557.

104. Cinzano, P.; Falchi, F.; Elvidge, C.D. The first world atlas of the artificial night sky brightness. Mon. Not. R. Astron. Soc. 2001, 328, 689-707.

105. Longcore, T.; Rich, C. Ecological light pollution. Front. Ecol. Environ. 2004, 2, 191-198.

106. Henderson-Sellers, A.; Hughes, N.A. 1979 3D-nephanalysis global total cloud amount climatology. Bull. Am. Meteorol. Soc. 1985, 66, 626-627.

107. Hamill, T.M.; D'Entremont, R.P; Bunting, J.T. A description of the Air Force real-time nephanalysis model. Wea. Forecast. 1992, 7, 288-306.

108. Crum, T.D. AFGWC Cloud Forecast Models; AFGWC Tech. Note 87/001; Air Force Global Weather Central: Omaha, NE, USA, 1987; p. 73.

109. Kidder, S.Q.; Vonder Haar, T.H. On the use of satellites in Molniya orbits for meteorological observation of middle and high latitudes. J. Atmos. Ocean. Tech. 1990, 7, 517-522.

110. Trishchenko, A.P; Garand, L.; Trichtchenko, L.D. Three-apogee 16-h highly elliptical orbit as optimal choice for continuous meteorological imaging of polar regions. J. Atmos. Ocean. Tech. 2011, 28, 1407-1422.

111. Holton, J.R. The influence of gravity wave breaking on the general circulation of the middle atmosphere. J. Atmos. Sci. 1983, 40, 2497-2507. 
112. Takahashi, M.; Boville, B.A. A three-dimensional simulation of the equatorial quasi-biennial oscillation. J. Atmos. Sci. 1992, 49, 1020-1035.

113. Makela, J.J. Imaging and modeling the ionospheric airglow response over Hawaii to the tsunami generated by the Tohoku earthquake of 11 March 2011. Geophys. Res. Lett. 2011, 38, L00G02.

114. Elvidge, C.D.; Cinzano, P.; Pettit, D.R.; Arvesen, J.; Sutton, P.; Small, C.; Nemani, R.; Longcore, T.; Rich, C.; Safran, J.; et al. The Nightsat mission concept. Int. J. Remote Sens. 2007, $12,2645-2670$.

115. Zhang, Q.; Seto, K.C. Can night-time light data identify typologies of urbanization? A global assessment of successes and failures. Remote Sens. 2013, 5, 3476-3494.

(C) 2013 by the authors; licensee MDPI, Basel, Switzerland. This article is an open access article distributed under the terms and conditions of the Creative Commons Attribution license (http://creativecommons.org/licenses/by/3.0/). 